\title{
Canyon effect and seasonal variability of deep-sea organisms in the NW Mediterranean: Synchronous, year-long captures of "swimmers" from nearbottom sediment traps in a submarine canyon and its adjacent open slope
}

\author{
C. Romano ${ }^{1,2}$, M.M. Flexas ${ }^{3}$, M. Segura ${ }^{1}$, S. Román ${ }^{1}$, N. Bahamon ${ }^{1}$, J.M. Gili ${ }^{4}$, A. Sanchez- \\ Vidal $^{5}$, D. Martin ${ }^{1}$ \\ ${ }^{1}$ Centre d'Estudis Avancats de Blanes (CEAB-CSIC) Carrer d'accés a la Cala Sant Francesc 14, 17300 Blanes \\ (Girona), Catalunya, Spain. \\ ${ }^{2}$ Scripps Institution of Oceanography, 8750 Biological Grade, Hubbs Hall, La Jolla, CA 92037, USA \\ ${ }^{3}$ California Institute of Technology, 1200 E. California Blvd, Pasadena, CA 91125, USA \\ ${ }^{4}$ Institut de Ciències del Mar (ICM-CSIC), Passeig Marítim de la Barceloneta 37-49, E-08003 Barcelona, Spain \\ ${ }^{5}$ GRC Geociències Marines, Departament de Dinàmica de la Terra i de l'Oceà, Facultat de Geologia, Universitat \\ de Barcelona, 08028 Barcelona, Spain
}

\begin{abstract}
Numerous organisms, including both passive sinkers and active migrators, are captured in sediment traps together with sediments. By capturing these "swimmers", the traps become an extraordinarily tool to obtain relevant information on the biodiversity and dynamics of deep-sea organisms. Here we analyze near-bottom swimmers larger than $500 \mu \mathrm{m}$ and their fluxes collected from eight near-bottom sediment traps installed on instrumented moorings deployed nearby Blanes Canyon (BC). Our data, obtained from November 2008 to October 2009 with a sampling rate of 15 days, constitutes the first year-long, continuous time series of the whole swimmers' community collected at different traps and bottom depths (from $300 \mathrm{~m}$ to $1800 \mathrm{~m}$ ) inside a submarine canyon and its adjacent open slope (OS). The traps captured 2155 specimens belonging to 58 taxa, with Crustacea (mainly Copepoda) and Annelida Polychaeta accounting for more than $90 \%$ of the total abundance. Almost half of the identified taxa (31) were only present in BC traps, where mean annual swimmer fluxes per trap were almost one order of magnitude higher than in the OS ones. Temporal variability in swimmer fluxes was more evident in $\mathrm{BC}$ than in OS. Fluxes dropped in winter (in coincidence with the stormy period in the region) and remained low until the following spring. In spring, there was a switch in taxa composition, including an increase of planktonic organisms. Additionally, we report drastic effects of extreme events, such as major storms, on deep-sea fauna. The impact of such extreme events along submarine canyon systems calls to rethink the influence of climate-driven phenomena on deep-sea ecosystems and, consequently, on their living resources.
\end{abstract}

Keywords: Submarine canyon; Mediterranean; sediment trap; planktonic and benthopelagic fauna; time-series data; hydromedusae.

\section{INTRODUCTION}

Deep-sea ecosystems represent the largest biome of the biosphere $(>65 \%$ of the earth surface). However, knowledge of their processes and biodiversity is still scant (Danovaro et al., 2010; Gage and Tyler 1991), and the Mediterranean Sea is not an exception. Being one of the most intensively investigated marine areas of the world and having high rates of endemism, its deep-sea fauna still remains poorly known (Coll et al., 2010). During the last years, the number of studies has increased, but they often focus on a specific or limited number of taxa and are conducted in a limited spatial or temporal scale (Danovaro et al., 2010). 
It is widely accepted that submarine canyons, especially those deeply indenting the continental shelf like Blanes Canyon (NW Mediterranean), have a very important role in channeling energy and matter from coastal areas to the deep ocean basin (Canals et al., 2013 and references herein). The downward particle fluxes and sediment accumulation rates inside canyons are generally higher than those recorded in the open slope (Palanques et al., 2008 and references therein). As a consequence of enhanced transport and fluxes, submarine canyons have a strong influence on deep-sea fauna (Company et al., 2008; Sardà et al., 2009), resulting in more productive and diverse planktonic and benthic communities in comparison to those found over open slopes (Vetter and Dayton, 1998; Gili et al., 1999; De Leo et al., 2010, Romano et al., 2013a) Processes generating advective fluxes canalized through the canyon, including large storms, river floods, dense shelf water cascading (DSWC) and trawlinginduced resuspension (Martín et al., 2014; Pusceddu et al., 2014; Puig et al., 2012), have therefore strong impact in the functioning of deep habitats. In particular, DSWC has been related to drastic changes in the population dynamics of decapods and temporary fishery collapses (Company et al., 2008). The influence of increased downward particle fluxes caused by bottom trawling along the canyon flanks on benthic meiofaunal assemblages has been recently discussed in Román et al. (2016). However, the effects of shelf-originated phenomena on the ecology and variability of other deep-sea fauna and its trophic web is still a matter of discussion.

With the aim of establishing links between upper water column processes and deep-sea food webs, the use of sediment traps deployed at different depths in the water column may certainly provide useful information, not only on sedimentary but also on biological processes. Although sediment traps were mainly designed to study vertical particle fluxes and sedimentation processes, they also allow assessing their dynamics, composition and origin, as well as to infer their links with existing biogeochemical cycles (Baker and Hickey, 1986). Numerous planktonic and epibenthic organisms are habitually captured alive by the traps and then become fixed together with the sediments. However, the ability of sediment traps to collect organisms has often been questioned (e.g. in Knauer and Asper, 1989), and traditionally, marine geologists labeled them as "swimmers", considering them as contaminants to be removed from samples to prevent interferences in particle flux mass estimates. Conversely, contrasting opinions consider swimmers as legitimate parts of the particle flux (Silver and Gowing, 1991) having a relevant contribution to the total particulate organic carbon trapped (Steinberg et al., 1998). In turn, the presence of some organisms can also interfere with sediment characteristics. For instance, the pteropod-downward escape response artificially increased the rates of capture, leading to overestimate the aragonite flux as a result of shell dissolution (Harbisson and Gilmer, 1986).

The fact is that sediment traps represent an extraordinarily useful tool to capture planktonic and benthopelagic organisms, especially in environments difficult to access, and to preserve them in good conditions. They provide complementary and relevant information to approach the biodiversity and dynamics of a wide range of deep-sea species. For instance, sediment traps are the only sampling method that can be used during long periods of sea-ice cover in the Arctic. Makabe et al. (2010) used them to demonstrate the existence of shifts in species composition related with the length of the sea ice cover period and nutrient availability. Sediment traps were also used to investigate the seasonal and interannual pattern of planktonic Crustacea in the Greenland Sea (Seiler and Brandt, 1997; Kraft et al., 2013; Nöthig et al., 2016). The observed differences between multi-net and trap samples in species composition and biomass allowed Seiler et al. (1997) to discuss on the significance of the abiotic influence of the sampling method vs. the biotic one caused by the active swimming behavior of some species into the traps. 
Several studies focusing on swimmers found in sediment traps have been recently carried out in the Mediterranean Sea, mainly within the frame of geological studies. In terms of biodiversity, these studies lead both to the description of new species, genera, and even families, of cnidarians and polychaetes, as well as to the re-description of other species based on the analysis of new morphological features (Gili et al., 1998, 1999, 2000; Sardá et al., 2009, Sevastou et al., 2012). Others revealed that canyons in the North Western Mediterranean Sea host unique and specific hydromedusa populations (Bouillon et al., 2000; Gili et al., 1999, 2000). The relevance of these studies is high, specially considering that most of them were carried out in submarine canyons, where sampling with traditional devices is always difficult (Gili et al., 1999).

Sediment traps have seldom been used to approach biotic processes in the Mediterranean Sea. To the best of our knowledge, there are only two studies dealing with the temporal variability of deep-sea organisms caught in near-bottom sediment traps (GuidiGuilvard et al., 2009, Danovaro et al. 2017). The first one provides relevant data on the temporal variations in organism fluxes and species composition of swimmers collected continuously during more than two years in a single station at the distal part of a submarine canyon, as well as on their relationships with environmental variables (Guidi-Guilvard et al., 2009). A more recent study (Danovaro et al., 2017) compares shallow and near-bottom zooplankton assemblages in three different geographical sub-basins of the Mediterranean Sea (Danovaro et al. 2017).

The fact that sediment traps provide simultaneous time series of both organisms and environmental data may be crucial for the understanding of processes controlling the changes in population structure of the target species. However, there are some obvious drawbacks in using sediment traps to study organisms. Among them, there is the difficulty to obtain replicates (which precludes the use of parametric statistics). Having this in mind, the amount of non-parametric options is fortunately far from negligible and should certainly allow scientists to go far beyond purely qualitative analyses with this kind of data, whose relevancy would otherwise be dismissed. Moreover there is a possible influence of behavior of the organisms in the captures (Harbison and Gilmer 1986), which make difficult to compare data from trap-caught organisms with quantitative abundance data obtained by plankton nets. Nevertheless, comparing the simultaneous, synchronized and continuous swimmer fluxes obtained from different locations and depths allow us to gather new and important information on the spatial and temporal variability of zooplankton and benthopelagic fauna.

In this paper we present the first time series of "swimmers" collected continuously over one-year period in near-bottom sediment traps moored inside and outside a submarine canyon, and its adjacent open slope, which allowed us to analyze and correlate the variations in fluxes and composition of swimmers with the main environmental variables (currents, storms, and sediment composition) of the study area.

\section{STUDY AREA}

NW Mediterranean Sea shelves and slopes are carved by a variety of submarine canyons that densely incise the Gulf of Lions and the Catalan margins (Lastras et al., 2011). The largest one in the area is Blanes Canyon (Fig. 1), which measures $184 \mathrm{~km}$ in length, with a nearly N-S trending course in its shelf-incised section (the canyon head), followed by a meandering course with a flat-floored channel at the base of continental slope. The canyon reaches a maximum width of $20 \mathrm{~km}$ at its deepest part, where it turns to a $\mathrm{W}$-E course before outflowing to the lower Valencia Channel at ca. $2600 \mathrm{~m}$ depth. The upper canyon is located at ca. $60 \mathrm{~m}$ depth and at ca. $4 \mathrm{~km}$ from the coastline where Tordera River reaches the sea (Amblas et al., 2006). 
The Northern Current (NC) is one of the main sources of flow variability in the area, with deep flow intensifications inside and along the axis of the canyon related to the $\mathrm{NC}$ offshore displacements (Flexas et al. 2008; Jordà et al., 2013). The topography of the canyon walls plays a major role in current variability, with the unidirectional south westward direction prevailing at the sharp western flank, favoring particle transport from the upper canyon to the deep basin, and the non-erosional hydrodynamic conditions at the smoother eastern flank, recovering less particulate material, mainly associated with hemipelagic sedimentation processes (Zúñiga et al., 2009).

Particle transport through the canyon is event-dominated, with maximum downward fluxes being related with storms, winter river discharges, intensification of the Northern Current and DSWC (Zúñiga et al., 2009; López-Fernandez et al., 2013; Puig et al, 2015). An additional source of variability in particle fluxes that certainly cannot be discarded derives from anthropogenically-mediated resuspension processes linked to trawling activities, in a similar way as demonstrated in the nearby La Fonera submarine canyon (Puig et al., 2012; Martín et al, 2014; Puig et al, 2015). Blanes Canyon and its adjacent margins are indeed important trawling areas, and it has been suggested that the structure and composition of the canyon-axis benthic assemblages may also be affected by this anthropogenic resuspension through flooding along lateral canyon gullies (Román et al., 2016). The most important (from an economical point of view) target species captured by trawling is the deep-water rose shrimp, Aristeus antennatus (Risso, 1816), which supports a specialized commercial fleet that has been fishing in the area for over 60 years (Sardà et al., 2009; Ramírez -Llodrà et al., 2010).

\section{MATERIAL AND METHODS}

\section{$\underline{\text { Sampling stations }}$}

Eight current meters paired with respective sediment traps were deployed near the bottom of the seafloor inside and outside Blanes Canyon from November 2008 to October 2009. Four current meter/trap pairs were placed along the canyon axis (BC), at 300, 900, 1200 and $1500 \mathrm{~m}$ bottom depth, and another four over the SW adjacent Open Slope (OS), at 900, 1200, 1500 and $1800 \mathrm{~m}$ bottom depth (Table 1). All moorings were equipped with a Technicap PPS3 sequential-sampling sediment trap at about $25 \mathrm{~m}$ above the bottom (hereafter, "mab") and a current meter with temperature sensor (Aanderaa RCM7/9) $5 \mathrm{~m}$ below the trap. The OS moorings were additionally equipped with near-bottom temperatureconductivity sensors (Microcat Seabird 37). The OS mooring at $1500 \mathrm{~m}$ depth was also equipped with one additional trap and current-meter pair, at $900 \mathrm{~m}$ (OS1500M, Fig. 1 and Table 1). All devices were calibrated before use. The temperature sensor at BC900 did not work. Mechanical failures led to data loss in velocity measurements at OS1500, and in temperature data at OS1800.

The Technicap PPS3 trap has a cylindrical-conical shape, with a 2.5 height-diameter ratio and a sampling area of $0.125 \mathrm{~m}^{2}$. Each trap was equipped with twelve $250 \mathrm{ml}$ receiving cups to collect the sediment, mounted on a mechanical system that rotates at programmed time intervals. Prior to deployment, receiving cups were carefully washed, rinsed with seawater and filled with a 5\% formaldehyde solution in filtered sea water (buffered with sodium borate) to reduce particle degradation and prevent possible problems caused by the action of live organisms that could interfere in later analysis. During the course of the experiment, all traps stayed open for intervals of 15-16 days except those of the BC1200 and OS1200 moorings, which were scheduled for twice that resolution (i.e. 8 days). These two 
higher resolution data sets were later pooled over 15-day interval for comparison with the others. After recovery, the samples were stored at $2-4{ }^{\circ} \mathrm{C}$ in the dark until processed in the laboratory, following Heussner et al. (1999).

Four cruises (PROMETEO I, II, III and IV) were conducted on board the oceanographic vessel $R V$ Garcia del Cid. During each cruise, maintenance operations of the moorings were carried out, sediment traps were retrieved and new traps were deployed.

\section{$\underline{\text { Swimmers }}$}

The materials collected in the sediment traps were initially sieved through a $1 \mathrm{~mm}$ poresize mesh to retain large-sized particles and swimmers. As the study dealt with macrofauna, the remaining sediments were gently sieved through a $500 \mu \mathrm{m}$ pore-size mesh. The retained swimmers were later sorted under a binocular stereomicroscope. Smaller organisms typically belonging to meiofaunal taxa (e.g., Nematoda) were not considered in this study. The remaining sediments were divided into aliquots to perform all relevant analyses (see procedures in López-Fernandez et al., 2013). All sorted swimmers were preserved in a 5\% formaldehyde solution until identified in the laboratory to the lowest possible taxonomical level (except for Copepoda) using stereomicroscopy and light microscopy.

Some traps suffered technical problems, mainly due to failures of the rotation engine (Fig. 2). These failures were considered as gaps in the time series, with the actual lack of swimmers in the traps being represented by zeros.

All sorted organisms were counted in order to obtain a general pattern of taxa distribution and abundance among the different locations, depths and seasons (see following section for details). All organisms that showed clear signs of decomposition and were considered dead organisms before their arrival in the traps were excluded from the present analysis. Swimmer abundances were standardized according to sampling area and capture time, leading to flux units, i.e. individuals $\mathrm{m}^{-2} \mathrm{~d}^{-1}$ : Number of individuals / sampling area $\left(0.125 \mathrm{~m}^{2}\right) /$ sampling days.

We present abundance, fluxes and composition of swimmers from all sediment traps. However, in order to evaluate similarities and differences related to nominal depth and location we focus our discussion on the near-bottom traps. Therefore the only sediment trap at intermediate depths (OS1500M) is not analyzed in detail.

\section{Statistical analyses}

Permutation multivariate analysis of variance PRIMER v6 \& PERMAVOVA+ software was used for multivariate analyses (Clarke and Gorley, 2006). Organism flux data (ind. $\mathrm{m}^{-2} \mathrm{~d}^{-}$ ${ }^{1}$ ) were first organized into a sample $v s$. taxa matrix. To assess spatial variations in swimmer fluxes and composition between locations (BC vs. OS), non-Metric Multidimensional Scaling (MDS) ordination using Bray-Curtis similarity-measure after a square-root transformation was carried out over a matrix constructed with the mean annual flux of taxa (pooled by Class) per trap. An analysis of similarities by randomization/permutation test (ANOSIM) was also performed.

To compare spatial-temporal variations in swimmer fluxes and composition at two different locations (BC vs. OS) only complete and concurrent data series were considered. Data from BC900, BC1200, OS900 and OS1200 fulfilled this requirement, while those from BC1500, OS1500 and OS1500M were excluded due to gaps. Two matrices were constructed considering different levels of taxonomic grouping $v$ s. each 15-day sample: the first matrix included all identified taxa; the second matrix used family as the lowest taxonomic level. Samples devoid of organisms were nevertheless included in the matrix, because zeros were 
unevenly distributed throughout the year, and more than $50 \%$ corresponded to a particular extreme storm event (26 December 2008), thereby providing meaningful information. Thus, a MDS was performed on square-root transformed data using the zero-adjusted Bray-Curtis similarity. Differences in sample composition were analyzed by PERMANOVA with a fully crossed design. Location (2 levels: BC vs. OS), Depth (2 levels: 900 vs. $1200 \mathrm{~m}$ depth) and Season (4 levels: autumn, winter, spring, summer) were treated as fixed factors.

Similarity percentages-species contributions analysis (SIMPER) was carried out in all cases to obtain the percentage contribution of each taxon to the similarity within, and the dissimilarity between, groups of samples.

Species numbers and diversity indices (S, number of species; H'( $\log 2)$, Shannon index) were also calculated with the PRIMER routine DIVERSE. As mentioned above, Copepods were not identified beyond Class, and therefore were not included in diversity estimates.

\section{Time-series analyses and correlation with environmental drivers}

Environmental variables, including water temperature, current speed, sediment fluxes (total mass flux, TMF; time-weighted fluxes, TWF), organic carbon vs. total nitrogen ratio (OC:TN), and opal (biogenic silica) (López-Fernández et al., 2013) are used here to calculate cross-correlations with swimmer abundances, as well as to identify potential temporal lags in organism responses. For the correlation analysis we used the value of each environmental variable averaged over the period during which each receiving cup was open. We ran the correlation analyses only for $\mathrm{BC} 300, \mathrm{BC} 900$ and $\mathrm{BC} 1200$, where swimmer abundance and the recording times led to large enough data sets. Swimmer abundance was log transformed. Given that the sampling interval of BC's sediment traps was of 15 days, our correlations have, accordingly, discrete time steps of 15 days. We upper-bounded our cross-correlation analysis to a maximum of 75-day lags (5 lags).

\section{RESULTS}

\section{Environmental conditions}

As reported in López-Fernández et al. (2013), several storms occurred during the study period. On four occasions (Nov. 2008, Dec. 2008, Jan. 2009, Apr. 2009), they had an impact on the near-bottom current record inside the canyon (Fig. 3; see also López-Fernández et al., 2013). A dry storm (i.e., without river discharge) on 28 November 2008 induced maximum SW current velocities along the canyon's main axis, reaching $22 \mathrm{~cm} \mathrm{~s}^{-1}$ at BC900, $23 \mathrm{~cm} \mathrm{~s}^{-1}$ at $\mathrm{BC} 1200$, and $14 \mathrm{~cm} \mathrm{~s}^{-1}$ at BC1500. The most dramatic storm ever recorded in the area, with a return period of $\sim 100$ years, took place in 2008 on December 26 (Sánchez-Vidal et al., 2012). This episode included intense rainfall, a discharge of $50 \mathrm{~m}^{3} \mathrm{~s}^{-1}$ of the nearby Tordera River, significant wave heights $>2 \mathrm{~m}$ over $65 \mathrm{~h}$, maximum wave heights of $8 \mathrm{~m}$, and near-bottom currents of $\sim 70 \mathrm{~cm} \mathrm{~s}^{-1}$ at BC300, $27 \mathrm{~cm} \mathrm{~s}^{-1}$ at BC900, $32 \mathrm{~cm} \mathrm{~s}^{-1}$ at BC1200, and $25 \mathrm{~cm} \mathrm{~s}^{-1}$ at BC1500. In 2009, the January 24, and April 25 storms were more moderate. Significant wave heights $>2 \mathrm{~m}$ were only detected for a few hours, and maximum wave heights were smaller than $3.5 \mathrm{~m}$. The January 2009 storm led to river discharges of up to $38 \mathrm{~m}^{3} \mathrm{~s}^{-1}$, and near-bottom currents of $19 \mathrm{~cm} \mathrm{~s}^{-1}$ in BC900 and $28 \mathrm{~cm} \mathrm{~s}^{-1}$ in BC1200. The April 2009 storm led to nearbottom currents of $23 \mathrm{~cm} \mathrm{~s}^{-1}$ in BC900 and $27 \mathrm{~cm} \mathrm{~s}^{-1}$ in BC1200.

In February 2009, moorings inside BC registered local formation of Western Mediterranean Intermediate Water (WIW), as confirmed by temperatures of $12.14^{\circ} \mathrm{C}$ and speeds up to $45 \mathrm{~cm} \mathrm{~s}^{-1}$ at BC300 (Fig. 3). Arrival of new Western Mediterranean Deep Water (nWMDW) from March to June 2009 produced a substantial increase in near-bottom current 
speed, a decrease in temperature, and an increase in salinity inside and outside the canyon (Figs. 3 and 4). Inside the canyon, the arrival of nWMDW was most evident in the temperature record at $1200 \mathrm{~m}$ depth (Fig. 3).

\section{$\underline{\text { Swimmers }}$}

Throughout the sampling period, 220 receiving cups were recovered and processed. Traps captured a total of 2,155 specimens belonging to 58 taxa (ranging from species to order) included in seven higher taxa (Table 2, Fig. 5). Crustacea were the most abundant taxa, mainly due to the contribution of Copepoda ( $>70 \%$ of the total abundance), followed by Annelida Polychaeta. The sum of both taxa accounted for more than $90 \%$ of the total abundance. The contribution of the remaining taxa was in all cases less than $5 \%$ of the total abundance (Fig. 5).

Mean annual swimmer flux per trap inside BC was almost one order of magnitude higher than in OS (15.4 vs. 2.1 ind. $\mathrm{m}^{-2} \mathrm{~d}^{-1}$, respectively) (Table 2, Fig. 6a). The highest annual fluxes inside BC were recorded from 300 to $1200 \mathrm{~m}$ depth, ranging from 18.3 to 15.9 ind. $\mathrm{m}^{-2} \mathrm{~d}^{-1}$, and decreased to 6.7 ind. $\mathrm{m}^{-2} \mathrm{~d}^{-1}$ at $1500 \mathrm{~m}$ depth.

Copepod abundances were considerably higher in BC than in OS (mean annual fluxes 11 vs. 5 ind. $\mathrm{m}^{-2} \mathrm{~d}^{-1}$, respectively) and decreased with increasing depth both in BC and in OS, while their contribution decreased with depth in $\mathrm{BC}$ but not in OS (Fig. 6a and 6b). In BC, the swimmer fluxes (excluding copepods) increased with depth, reaching a maximum at BC1200, and then decreased towards BC1500 (Fig 6A). On the other hand, the relative abundances of Annelida and non-copepod Crustacea increased with increasing depth until the deepest trap (Fig. 7a). On the contrary, the abundance of Polychaeta in OS traps decreased with depth until OS1500, and then increased in the deepest one. No clear trends in the number of specimens, or in contributions of non-copepod crustaceans were observed in OS traps (Fig. 7a and 7b).

Of a total of 58 identified taxa, more than half (31) were only present in BC traps. Among polychaetes, larval forms (mainly of Glyceridae and Spionidae, but also Poecilochaetidae) were twice the number of adults. Surprisingly, the second more abundant taxa in BC was an elasipodid holothurian identified as Penilpidia ludwigii (von Marenzeller, 1893). Five specimens were found in the BC1500 trap from December to February and the remaining 15 were present in $\mathrm{BC} 1200$ from November to September. On the other hand, five taxa were found only in OS, amongst which, the most abundant was a planktonic polychaete belonging to the genera Pellagobia. All of them were captured in spring and autumn at the intermediate water trap (OS1500M), except for one specimen captured in autumn in the near bottom trap (OS1200). Adult polychaetes were more abundant in late autumn/early winter and mainly belonged to Acrocirridae, Hesionidae and Syllidae at BC300 and to Spionidae at BC900, BC1200 and OS900. Syllids were also present at BC900 and BC1200 in late summer.

Overall, BC showed richer swimmer assemblages than OS, although the difference was not significant ( $\mathrm{t}$-test, $\mathrm{p}>0.05$ ) and the number of taxa varied among depths. The most diverse assemblage was captured at BC1200 (39 taxa, Table 2), which was also the second largest in terms of abundance after BC900 (Fig. 7A, 7B). Copepoda highly dominated in BC, while individuals were distributed more evenly among the different taxa in OS, as shown by the higher Shannon diversity index in OS (H'OS $=3.00)$ than $\mathrm{BC}\left(\mathrm{H}^{\prime} \mathrm{BC}=2.00\right)$, when Copepoda were included in the analysis.

Besides the above-mentioned differences in abundance and diversity, swimmer fluxes also changed in composition between BC and OS. The MDS analysis performed on the sample vs. taxa-abundance (pooled by Class) matrix illustrates a significant difference between locations (Fig. 8), as confirmed by the ANOSIM ( $\mathrm{R}=0.856 ; \mathrm{p}<0.01)$. The withinaverage similarities were similar for both areas (BC: 76.52\%; OS: 76.63\%). As expected, 
copepods were the first contributor to similarity in both locations, although with highest percentage in BC (nearly 50\%), where they were followed by Annelida, non-copepod Crustacea (19.07\% and 15.75\% respectively), and Mollusca (less than 10\%). For OS, the differences between contributions of the classes accounting for up the $90 \%$ of the abundances (non-copepod Crustacea, Mollusca, Annelida, and Cnidaria, in order of relevance) were much less pronounced. In both locations, non-copedod Crustacea and Mollusca were mainly represented by Ostracoda and Pteropoda respectively. Regarding dissimilarity (BC vs. OS: $45.21 \%$ ), copepods accounted for the 50\%, followed by Annelida (15\%), while the contributions of the following classes were lower than 10\%. All taxa that contribute up to 90\% of averaged dissimilarity, except Chordata, showed higher averaged abundances inside the canyon.

The two complete and concurrent data series, i.e. BC900-OS900 and BC1200- OS1200, showed significant effects for location, depth and season (PERMANOVA, $p<0.01$, Table 3 ) and also for the interaction between location and season (PERMANOVA, $p<0.01$ ). The pairwise test indicates significantly higher abundances in BC than in OS in every season except winter, when $\mathrm{BC}$ fluxes dropped to lowest values for most of the taxa. On the open slope, only spring generally presented significantly higher abundances than summer, while BC presented higher variation among seasons (Table 3). The nMDS plot showed a good segregation between BC and OS, even though some samples appear detached from the two main groups (Fig. 9a). The SIMPER results show high average dissimilarities between groups and low average similarity within groups for the factor 'location-season' (Table 4). For the pairs significantly differing according to PERMANOVA, copepods were the main contributors to dissimilarity, accounting from $22 \%$ (OS-Sp vs. OS-Sm) to almost $50 \%$ (BC-A vs. BC-W). Inside the canyon, copepods and non-copepod Crustacea were less abundant during the winter. The hydromedusae Parateclaia euromarge (Bouillon et al., 2000) appeared as the second contributor to the dissimilarity among seasons in $\mathrm{BC}$, being more abundant in summer and absent in winter and autumn. Moreover, the polychaete larvae in BC showed the highest abundance in summer, but were also present in winter with a slightly lower abundance. It is worth mentioning that, although all specimens were pooled as Polychaeta larvae for the analysis, all larvae found in summer belonged to the Spionidae while all those collected in winter, mainly at BC1200, belonged to Glyceridae (Fig. 12). The Holothuroidea (exclusively $P$. ludwigii) were also among the first five contributors inside BC, showing similar abundances during all seasons except in spring, when their abundance was lower. The Spionidae were most abundant in autumn and were responsible for $6.8 \%$ of the differences between autumn and winter. Finally, the hyperid amphipods were less abundant in winter and spring and the Syllidae were recorded only during summer (Table 4).

Regarding OS, only spring and summer differed significantly between seasons. Copepods were the main contributors to this dissimilarity, being more abundant in spring than in summer, together with cavoliniid mollusks and adult polychaetes. On the contrary, hyperid amphipods were more abundant in summer (Fig. 13). Tunicata and non-copepod Crustacea were present in spring and not in summer.

Time-series analyses and correlation with environmental drivers.

Temporal variation in swimmer fluxes was more evident in BC than in OS (Fig. 10 and 11). At 300, 900 and $1500 \mathrm{~m}$ depth, BC-swimmer fluxes dropped in late December in all traps and remained low or even null till April. Two abundance peaks were recorded in early May (98 ind. $\left.\mathrm{m}^{-2} \mathrm{~d}^{-1}\right)$ and in September $\left(58\right.$ ind. $\left.\mathrm{m}^{-2} \mathrm{~d}^{-1}\right)$ at BC900. At $1200 \mathrm{~m}$, the fluxes appeared to increase earlier (38 ind. $\mathrm{m}^{-2} \mathrm{~d}^{-1}$, in early March), and further on fluctuated around 41 ind. $\mathrm{m}^{-2}$ $\mathrm{d}^{-1}$ on average till May. 
In OS, swimmer fluxes were generally lower. At OS900 a relative increase of up to 13 ind. $\mathrm{m}^{-2} \mathrm{~d}^{-1}$ was observed in November-December. In March-April, maximum swimmer fluxes sporadically rose up to 12 and 5 ind. $\mathrm{m}^{-2} \mathrm{~d}^{-1}$ at OS1200 and OS1800, respectively.

Copepoda represented $76 \%$ and $73 \%$ of total abundance in BC and OS, respectively, and their distribution generally matched that of total swimmer abundance (Fig 10 and 11). Apart from copepods, infaunal taxa like adult polychaetes, gastropods and bivalves were more abundant in autumn-early winter. From January to May all taxa fluxes decreased, except those for glycerid larvae, which showed an increase from March to April at BC1200. Spionid larvae, Ostracoda, and Cnidaria (e.g. P. euromarge) fluxes increased from early May to September, both in BC900 and BC1200 (Fig. 12).

Total swimmer abundance was significantly and positively correlated with TWF, with a 15-day lag, and significantly and negatively correlated with OC:TN at zero-day lag (Table 5). At BC900, swimmers were significantly and positively correlated with TWF, with lags ranging from zero- to 45-day lag. The maximum correlation $(r=0.7)$ was recorded with a 15day lag. Furthermore, we found significant negative cross correlations with opal percentage and with current velocity, which were the highest correlations recorded without lag.

At BC1200, swimmers were significantly and positively correlated with the OC:TN ratio at zero- and at 15-day lag. Although in this case the correlation of swimmers with TWF showed a positive trend, this was statistically not significant. Swimmers were negatively correlated with both, water temperature and current velocity at zero lag and at 15-day lag, indicating that an increase in current speed led to a decrease in swimmer fluxes within the following 15-day period (Table 5). Swimmers also showed a significant negative correlation with opal percentage at zero- and 15-day lags.

\section{DISCUSSION}

\subsection{Abundance and composition of swimmers}

Total swimmer fluxes inside BC were one order of magnitude higher than in OS and mirrored the differences recorded for TMF (18.3 vs. $1.8 \mathrm{~g} \mathrm{~m}^{-2} \mathrm{~d}^{-2}$ in BC and OS, respectively) (López-Fernández et al., 2013). This supports that BC acts as a preferential conduit for particle transport from the shelf to the deep basin, but also suggests that it may play a major role in controlling the regional distribution of deep-sea benthopelagic organisms. Our results also support the view of canyons acting as hotspots for fauna diversity and biomass, as previously reported for benthic communities (Román et al., 2016, Romano et al., 2013a, 2013b, Tecchio et al., 2013, Cartes et al., 2009; Sardà et al., 2009).

Our results on taxonomic composition agree with Cartes (1998), who studied the benthopelagic fauna in the benthic boundary layer of the Catalan continental slope, using both a Macer Giroq sledge (0.1-1.5 mab) and a plankton net (towed 13-55 mab), and found an overall dominance of copepods, high abundance of Ostracoda and gelatinous plankton, and dominance of hyperid amphipods among peracarid crustaceans (i.e., mysids, amphipods, isopods, and cumaceans). In our near-bottom traps, copepods highly dominated among swimmers collected both inside the canyon and over the adjacent open slope, and included planktonic organisms able to perform vertical migrations and to swim actively into the traps as previously found in other geographical areas (Matsuno et al. 2014; Makabe et al. 2016). Such dominance of copepods in near-bottom zooplankton agrees with previous reports in other areas of Mediterranean Sea like the Ligurian Sea off Nice (Guidi-Cuilvard et al. 2009; $2300 \mathrm{~m}$ deep), the Balearic Basin (Cartes et al., 2013; $1100 \mathrm{~m}$ deep) and the Adriatic Sea (Danovaro et al., 2017; $1050 \mathrm{~m}$ deep). However, this pattern contrasts with very recent findings in the Ionian Sea (Danovaro et al., 2017; $2250 \mathrm{~m}$ deep), that reported dominance of ostracods $(80 \%)$. In that particular case, high ostracod abundance seemed to be linked to 
temperature conditions and the scarcity of potential predators (Hydromedusae, Siphonophora).

Cartes (1998) also collected benthopelagic fishes (e.g., Cyclothone braueri; Jespersen and Taning, 1926) with an opening-closing plankton net towed at 13-55 mab. No fish were caught in our samples, likely due to the ability of fish to avoid the static traps. On the other hand, the suprabenthic fauna collected by Cartes (1998) showed a poor representation of polychaetes $(<0.03 \%)$, while they represented the second most abundant group in BC $(10 \%$, Fig. 5) and the second or third in OS (5-15\%, Fig. 5). The relatively high abundance of infaunal polychaetes (typically sedentary) in traps placed 25 mab, was previously reported in La Fonera Canyon (Sardá et al, 2009) and in the Alboran Sea (Danovaro et al., 2017). Transport processes in a highly turbulent environment, such as strong bottom currents and resuspension events typical of submarine canyon systems, may contribute to explain the presence of infaunal organisms in the traps. In BC, for instance, strong bottom-currents exceeding $20 \mathrm{~cm} \mathrm{~s}^{-1}$ were recorded down to $1200 \mathrm{~m}$ deep in several occasions during autumn and winter, and probably eroded and resuspended the first sediment centimeters, as reported in other deep-sea environments (Thistle et al., 1991). A possible anthropogenic influence that cannot be discarded is trawling-induced lateral transport of matter, which could also contribute to the arrival of resuspended sediments (and organisms within) from the canyon flanks (Román et al., 2016; Puig et al., 2012). The overall combination of different events and processes may thus have been responsible of bringing benthic taxa to the pelagic environment, explaining the occurrence of Acrocirridae, Hesionidae and Syllidae at BC300, as well as Spionidae (i.e., Prionospio sp., Paraprionospio sp. and Laonice sp.) at BC900 and BC1200 during the late autumn-early winter period. Finally, it is worth noting that some species found in BC, such as Prionospio, have a swimming reproductive phase linked to adult spawning, characterized by an enlargement of chaetae and parapodia that may improve flotation in comparison to a typically benthic form (Vasily Radashevsky, personal communication). Accordingly, this may constitute an alternative explanation for the presence of large adults $(2-3 \mathrm{~cm}$ in length in the case of $P$. elhersi) in our near-bottom sediment traps. The current lack of knowledge on the life history of these deep-sea species together with the scarceness of previous studies using sediment traps does not allow us to quantify the relative contribution of each of these possible underlying principles.

Total annual swimmer fluxes inside BC decreased progressively with increasing water depth. However, this trend is clearly influenced by copepods. By excluding this taxon, the highest fluxes of the remaining taxa were recorded at $1200 \mathrm{~m}$ deep. These results are consistent with both particle fluxes (López-Fernández et al., 2013) and sediment-dwelling meiofauna distribution patterns observed along the canyon axis (Román et al., 2016). An increase in particle fluxes, food availability and meiofaunal density was recorded at $1200 \mathrm{~m}$ deep compared with shallower and deeper stations along the canyon. This relative increase in TMF at $1200 \mathrm{~m}$ was attributed to lateral (horizontal) transport of sediment particles resuspended by the recurrent, daily trawling in canyon flanks (Roman et al., 2016). Such anthropogenically-driven process may be particularly important during spring and summer, when it is not masked by the effects of energetic winter events. Accordingly, it may be responsible for the increase in swimmer fluxes at BC1200 traps, supporting the postulated presence of an anthropogenic depocenter at these depths inside BC (Roman et al., 2016).

\subsection{Temporal variability and impact of coastal extreme events (storms)}

The weather conditions in the study area from late 2008 to early 2009 were particularly stormy (Fig. 3 and 4; López-Fernández et al., 2013). Extreme events like intense coastal storms are known to induce increases in bottom currents leading to sediment and particle 
resuspension that may converge from the shelf into submarine canyons (Palanques et al., 2006), a mechanism that we have already reported as a possible contributor to explain the presence of infaunal organisms in BC's traps during late autumn.

On $26^{\text {th }}$ of December 2008 the most severe storm recorded for several decades occurred in the area. Serious and well-documented damages on shallow continental shelf bottoms and the associated benthic assemblages were attributed to this particularly extreme coastal storm (Sánchez-Vidal et al., 2012; Mateo et al., 2012). Current speed increased up to $70 \mathrm{~cm} \mathrm{~s}^{-1}$ at BC head (BC300) (Sánchez-Vidal et al., 2012), reaching at least $25 \mathrm{~cm} \mathrm{~s}^{-1}$ in all stations along the canyon axis (Fig. 3). High current speeds were accompanied by high concentrations of probably resuspended sediments, as well as by high down-canyon particle fluxes reaching $1500 \mathrm{~m}$ deep (Sánchez-Vidal 2012; López-Fernández et al., 2013). Our results show that this event had a dramatic impact on the swimmer assemblages captured in our sediment traps, especially along the canyon axis.

Total swimmer fluxes decreased gradually during the mid-December stormy period, leading to a total absence of fauna following the December 26th storm, which lasted for months in the $300-$ to $1500-\mathrm{m}$ traps along BC. The negative correlations between swimmer abundances and the mean current velocity recorded with zero to 15-day lags at BC900 and BC1200, supports the latter as being among the major drivers affecting the swimmers. This influence was particularly evident during the major storm event, when current intensities were the highest at all stations (Fig. 3). Accordingly, speeds ranged from $25 \mathrm{~cm} \mathrm{sec}^{-1}$ at $1500 \mathrm{~m}$ depth to $70 \mathrm{~cm} \mathrm{sec}^{-1}$ at $300 \mathrm{~m}$ depth (López-Fernández et al., 2013), being thus certainly able to remove and wipe out potential swimmers from the water column. Presently, we do not have a plausible explanation for the negative correlations recorded at BC900 and BC1200 between swimmer fluxes and opal percentage. However, we feel the significance of this correlation may be a confounding factor explained by the fact that the lowest concentration of swimmers in winter occurs concurrently with increasing current velocity and also highest opal concentration, therefore causing an unrealistically good correlation between swimmers and opal.

Another outstanding feature after the December $26^{\text {th }}$ storm was the disappearance of typical benthic fauna in BC traps. Furthermore, despite the swimmer fluxes (mainly Copepoda) started to recover several months after, there was a substantial switch in faunal composition towards planktonic taxa (e.g., P. euromarge, Ostracoda, polychaete larvae). Accordingly, we postulate that the presence of benthic adult organisms among swimmers could be either linked to resuspension events and/or their reproductive behavior, while their absence could be an effect of the extremely high currents produced during the storm.

From March to early May, increased near-bottom current speed associated with the arrival of new Western Mediterranean Deep Water (nWMDW) was recorded in the study area (Fig. 3 and Fig. 4). This tongue of turbid cold water is related to winter dense shelf water cascading in the Gulf of Lions (Puig et al., 2013), arriving at the Blanes site a few months later, and is able to intensify bottom resuspension, as confirmed by the observed increase in particle fluxes in March (López-Fernández et al., 2013). The nutritional value associated to this late spring increase may have also been responsible for the abundant swimmer presence, including the maximum fluxes recorded for the dominant copepod at BC900 and BC1200. In turn, the presence of polychaete larvae, mainly glycerids from March and spionids later in spring, agrees with the highest abundances of meroplanktonic larvae reported during spring in shallow waters at Blanes Bay (Martin et al., 1997; Pinedo et al., 1996, 1997; Sardá et al., 1999).

In OS, the temporal variability of swimmer fluxes was less evident than in BC. The slight increase recorded during spring may be related to the OS maximum particle fluxes recorded in March 2009 that may be related to the arrival of nWMDW as well as to the 
surface phytoplankton bloom that enhanced Chl-a concentration and caused bioaggregate settling (López-Fernández et al., 2013).

Previous works have questioned trap collection efficiency under intense current speed conditions (Garner et al. 1997, Danovaro et al. 2017). However, over the course of our experiment, high values of TMF were recorded during stormy periods, with particularly large particle fluxes measured at BC1200 (López-Fernádez et al. 2013). This supports that our sediment traps were efficiently collecting material (and, thus, organisms) throughout the whole sampling period. We therefore consider as reliable data the absence of swimmers recorded not only during the stormy period but persisting after the currents dropped down..

5.3 Differences in swimmer abundance and composition between BC and OS: with new reports of species for BC

The near-bottom traps inside BC tended to capture a more diverse swimmer assemblage than traps in the adjacent OS at equivalent depths. Copepod fluxes (the most abundant taxa) were highest in BC, and they were a major contributor to the differences between $\mathrm{BC}$ and OS. Note that despite the relevance of this taxon, we only identified copepods at the Class level, therefore our data did not allow us to perform assemblage comparisons, neither to assess the relative relevance of the planktonic $v s$. benthic fractions between locations and depths.

Among the taxa captured only at $\mathrm{BC}$, the elasipodid holothurian P. ludwigii occurred only in the deepest traps (i.e., BC1200 and BC1500). This endemic Mediterranean species was originally described in the Eastern Mediterranean Sea by the Pola Expedition in 18901892, and much later rediscovered, in the same basin, by Fiege and Liao (1996). Pagès et al. (2007) reported this holothurian, for the first time, in the Western Mediterranean Sea, as being very abundant in sediment traps within La Fonera Canyon (the closest canyon north to BC) between 1200 and $1700 \mathrm{~m}$ depth. Our records confirm its presence in the Western Mediterranean, while providing strong support to both its absence in shallow depths and its association with submarine canyon environments., The occurrence of $P$. ludwigii in our sediment traps may be explained by resuspension of this gelatinous and light holothurian into the water column, as previously postulated for specimens from La Fonera Canyon. However, its presence into the trap may also be explained by lateral transport of particulate matter (either anthropogenically-mediated or not) and/or its swimming ability (Pagès et al., 2007). As in La Fonera Canyon, most BC specimens occurred in spring-summer, when an increase in organic particle fluxes was recorded (López-Fernández et al., 2013), suggesting that food availability may also be a plausible explanation for its seasonal recovery.

Cnidaria (mainly hydromedusae) were also more abundant in BC than in OS, in agreement with previous studies on new records and descriptions of fauna from other NW Mediterranean submarine canyons (Gili et al., 1998, 1999, 2000). According to those studies, the rate of Mediterranean endemism for deep-water hydromedusae raised to $50 \%$ of the currently known worldwide deep-sea hydromedusan fauna. The specific composition and abundance of the population differed from canyon to canyon and seemed to be related to vertical fluxes and topographic characteristics, as well as to their particular hydrographical and ecological features (Gili et al., 1998, 1999, 2000). Among the Hydromedusae collected in BC, $P$. euromarge, occurred mainly in the 900- to 1500-m traps; in addition, one specimen was also collected at OS1200. Previous to our study, this species was solely reported at 1000 $m$ depth in the Lacaze-Duthiers Canyon (north of BC, off the French south coastal margin of the Gulf of Lyons; Bouillon et al., 2000). In agreement with this previous report, our captures took place in spring and summer. Among the Hydromedusae, a specimen of Earleria araiae (Gili et al., 1999) and one of Teclaia recincolae Gili et al., (1999) were collected at OS1500 
and $\mathrm{BC} 1200$ respectively. Our findings extend their biogeographic distribution, as they were previously considered endemic of the Foix Canyon, south to BC (Bouillon et al., 2000).

Finally, we also report, for the first time, the presence of two species both in BC and OS, Solmaris leucostyla (Will, 1844) and Mitrocomella brownie (Kramp, 1930), which have never been found in any Mediterranean canyons investigated to date.

\section{CONCLUSIONS}

This study recorded for the first time the annual swimmer fluxes at different depths, simultaneously inside a submarine canyon and at its adjacent open slope. This allowed us to highlight the marked differences between the two habitats, which were true in terms of swimmer abundance, taxonomic composition and temporal variability.

Concerning specifically the cnidarians, our records confirm that BC hosts a novel deepsea fauna characterized by the presence of some species of Hydromedusae (e.g., P. euromarge and $E$ araiae, but also Ptychogastria asteroides (Haeckel, 1879) and Teclaia recincolae) known so far only from other western Mediterranean canyons (Bouillon et al., 2000). Last but not least, we also report, for the first time, the presence of two species, Solmaris leucostyla and Mitrocomella brownie, which inhabit both BC and OS and have never been found in any Mediterranean canyons investigated to date.

In addition to reporting the faunistic differences existing among Blanes and nearby canyons, our data are also singular in reporting a continuous time series on swimmer fluxes inside a canyon and along its slope in Mediterranean deep-sea. We demonstrate that swimmers were consistently more abundant in BC than in OS. Whether this supports the concept of submarine canyons as being biodiversity hot spots or just reflects the particular combination of hydrodynamic, geologic and anthropogenic circumstances allowing the traps to capture more organisms in $\mathrm{BC}$ than in OS remains a question to be solved in future studies. Conversely, we certainly prove the high temporal and seasonal variability occurring along the canyon axis.

Our results also demonstrate that extreme events such as major storms not only affected the shallow coastal bottoms, but also had more drastic effects on the deep-sea fauna than previously thought. This influence is certainly amplified along submarine canyon systems, thus opening new insights on how climate-driven phenomena may impact on deep-sea ecosystems and, consequently, on their living resources.

Acknowledgements

The authors would like to thank the crew of the R.V. Garcia del Cid, and colleagues from CSIC, UB, and other institutions for their help during the cruise. We are indebted to Prof. Antoni Calafat, and his team from the University of Barcelona, who deployed the sediment traps and sorted out the swimmers. Our research was supported by the PROMETEO research project (Ref. CTM2007-66316-C02-02/MAR) funded by the Spanish State Research Plan. This is a contribution to the Consolidated Research Group on Marine Benthic Ecology of the "Generalitat de Catalunya" (2014SGR120). CR received an International Outgoing Fellowship from the People Programme (Marie S. Curie Actions) of the European Union's Seventh Framework Programme (FP7/2007-2013) (www.DeepFall-project.eu) under the REA grant agreement N. PIOF-GA-2013-628146. The authors are grateful to two anonymous reviewers for their constructive comments and suggestions. 


\section{REFERENCES}

Amblas, D., Canals, M., Urgeles, R., Lastras, G., Liquete, C., Hughes-Clarke, J.E., Casamor, J.L., Calafat, A.M., 2006. Morphogenetic mesoscale analysis of the northeastern Iberian margin, NW Mediterranean Basin. Marine Geology 234, 3-20.

Baker, E.T., Hickey, B.M., 1986. Contemporary sedimentation processes in and around an active West Coast submarine canyon. Marine Geology 71, 15-34.

Bouillon, J., Pagès, F., Gili, J.M., Palanques, A., Puig, P., Heussner, S., 2000. Deep-water Hydromedusae from the Lacaze-Duthiers submarine canyon (Banyuls, northwestern Mediterranean) and description of two new genera, Guillea and Parateclaia. Scientia Marina 64, 87-95.

Canals, M., Puig, P., De Madron, X.D., Heussner, S., Palanques, A., Fabres, J., 2006. Flushing submarine canyons. Nature 444, 354-357.

Canals, M., Company, J.B., Martin, D., Sánchez-Vidal, A., Ramírez-Llodrà, E., 2013. Integrated study of Mediterranean deep canyons: novel results and future challenges. Progress in Oceanography 118, 1-27.

Cartes, J.E., 1998. Dynamics of the bathyal Benthic Boundary Layer in the northwestern Mediterranean: depth and temporal variations in macrofaunal-megafaunal communities and their possible connections within deep-sea trophic webs. Progress in Oceanography 41, 111-139.

Cartes, J. E., E. Fanelli, C. López-Pérez and M. Lebrato 2013. Deep-sea macroplankton distribution (at 400 to $2300 \mathrm{~m}$ ) in the northwestern Mediterranean in relation to environmental factors. Journal of Marine Systems 113: 75-87.

Cartes, J.E., Maynou, F., Fanelli, E., Romano, C., Mamouridis, V., Papiol, V., 2009. The distribution of megabenthic, invertebrate epifauna in the Balearic Basin (western Mediterranean) between 400 and $2300 \mathrm{~m}$ : Environmental gradients influencing assemblages composition and biomass trends. J. Sea Res. 61, 244-257.

Clarke, K.R., Gorley, R.N., 2006. PRIMERv6: UserManual/Tutorial (Plymouth).

Coll, M., Piroddi, C., Steenbeek, J., Kaschner, K., Ben Rais Lasram, F., Aguzzi, J., Ballesteros, E., Bianchi, C.N., Corbera, J., Dailianis, T., Danovaro, R., Estrada, M., Froglia, C., Galil, B.S., Gasol, J.M., Gertwagen, R., Gil, J., Guilhaumon, F., Kesner-Reyes, K., Kitsos, M.-S., Koukouras, A., Lampadariou, N., Laxamana, E., López-Fé de la Cuadra, C.M., Lotze, H.K., Martin, D., Mouillot, D., Oro, D., Raicevich, S., Rius-Barile, J., SaizSalinas, J.I., San Vicente, C., Somot, S., Templado, J., Turón, X., Vafidis, D., Villanueva, R., Voultsiadou, E., 2010. The biodiversity of the Mediterranean Sea: Estimates, patterns and treats PLoS ONE 5, e11842.

Company, J.B., Puig, P., Sardà, F., Palanques, A., Latasa, M., Scharek, R., 2008. Climate Influence on Deep Sea Populations. PLoS ONE 3, e1431.

Danovaro, R., Company, J.B., Corinaldesi, C., D'Onghia, G., Galil, B., Gambi, C., Gooday, A.J., Lampadariou, N., Luna, G.M., Morigi, C., Olu, K., Polymenakou, P., RamírezLlodrà, E., Sabbatini, A., Sardà, F., Sibuet, M., Tselepides, A., 2010. Deep-sea biodiversity in the Mediterranean Sea: The known, the unknown, and the unknowable. PLoS ONE 5, 125.

Danovaro R. , L. Carugati, A. Boldrin, A. Calafat, M. Canals, J. Fabres, K. Finlay, S. Heussnerg, S. Miserocchi and A. Sanchez-Vidal, 2017. Deep-water zooplankton in the Mediterranean Sea: Results from a continuous, synchronous sampling over different regions using sediment traps. Deep-Sea Research Part I Oceanographic Research Papers. 
De Leo, F.C., Smith, C.R., Rowden, A.A., Bowden, D.A., Clark, M.R., 2010. Submarine canyons: Hotspots of benthic biomass and productivity in the deep sea. Proceedings of the Royal Society B: Biological Sciences 277, 2783-2792.

Fiege, D., Liao, Y., 1996. Penilpidia ludwigi (Marenzeller, 1893) (Holothuroidea. Elpidiidae) rediscovered from the eastern Mediterranean Sea. In: Uiblein, F., Ott, J., Stachowitsch, M. (Eds.), Deep-sea and Extreme Shallow-Water Habitats: Affinities And Adaptations. Biosystematics and Ecology Series, vol. 11, pp. 61-66.

Flexas, M.M., Boyer, D.L., Espino, M., Puigdefäbregas, J., Rubio, A., Company, J.B., 2008. Circulation over a submarine canyon in the NW Mediterranean. Journal of Geophysical Research C: Oceans 113. 18.

Gage J.D., Tyler P.A., 1991. Deep sea biology: A natural history of organisms at the deep-sea floor. Cambridge: Cambridge University Press. 504 p.

Gili, J.-M., Bouillon, J., Pagès, F., Palanques, A., Puig, P., Heussner, S., 1998. Origin and biogeography of deep-water Mediterranean hydromedusae including the description of two new species collected in submarine canyons of Northwestern Mediterranean. Scientia Marina 62, 113-134.

Gili, J.-M., Bouillon, J., Pagès, F., Palanques, A., Puig, P., 1999. Submarine canyons as habitats of prolific plankton populations: three new deep-sea Hydroidomedusae in the western Mediterranean. Zoological Journal of the Linnean Society. 125, 313-329.

Gili, J.-M., Pagès, F., Bouillon, J., Palanques, A., Puig, P., Heussner, S., Calafat, A., Canals, M., Monaco, A., 2000. A multidisciplinary approach to the understanding of hydromedusan populations inhabiting Mediterranean submarine canyons. Deep-Sea Research Part I-Oceanographic Research Papers 47, 1513-1533.

Guidi-Guilvard, L.D., Thistle, D., Khripounoff, A., Gasparini, S., 2009. Dynamics of benthic copepods and other meiofauna in the benthic boundary layer of the deep NW Mediterranean Sea. Marine Ecology Progress Series. 396, 181-195.

Harbison G.R., Gilmer R.W., 1986. Effects of animal behavior on sediment trap collections implications for the calculation of aragonite fluxes. Deep Sea Res 33, 1017-1024.

Heussner, S., Durrieu de Madron X., Radakovitch O., Beaufort L., Biscaye P.E., M. M. Flexas, M. Espino and A. Calafat, 2013. Deep flow variability in a deeply incised Mediterranean submarine valley (Blanes canyon). Progress in Oceanography 118: 47-60.

Kraft, A., Bauerfeind, E., Nöthig, E.-M., Klages, M., Beszczynska-Möller, A., Bathmann, U.V., 2013. Amphipods in sediment traps of the eastern Fram Strait with focus on the lifehistory of the lysianassoid Cyclocaris guilelmi. Deep Sea Research Part I: Oceanographic Research Papers 73, 62-72.

Knauer G.A., Asper V., 1989. Sediment trap technology and sampling. U.S. GOFS Planning Report no. 10. U.S. GOFS Planning Office, Woods Hole, MA, p 94

Lastras, G., Canals, M., Amblas, D., Lavoie, C., Church, I., De Mol, B., Duran, R., Calafat, A.M., Hughes-Clarke, J.E., Smith, C.J., Heussner, S., 2011. Understanding sediment dynamics of two large submarine valleys from seafloor data: Blanes and La Fonera canyons, northwestern Mediterranean Sea. Mar. Geol. 280, 20-39.

López-Fernández, P., Calafat, A., Sánchez-Vidal, A., Canals, M., Flexas, M.M., Cateura, J., Company, J.B., 2013. Multiple drivers of particle fluxes in the Blanes submarine canyon and southern open slope: Results of a year round experiment. Progress in Oceanography 118, 95-107.

Makabe, R., Hattori, H., Sampei, M., Ota, Y., Fukuchi, M., Fortier, L., Sasaki, H., 2010. Regional and seasonal variability of zooplankton collected using sediment traps in the southeastern Beaufort Sea, Canadian Arctic. Polar Biology 33, 257-270.

Mateo, M.A. and Garcia T. (Eds) 2012. Assessment of the ecological impact of the extreme storm of Sant Esteve (26 December 2008) on the littoral ecosystems of the north 
Mediterranean Spanish coast. Final Report (PIE 200430E599). CEAB-CSIC, Blanes, pp.319.

Matsuno, K., A. Yamaguchi, A. Fujiwara, J. Onodera, E. Watanabe, I. Imai, S. Chiba, N. Harada and T. Kikuchi, 2014. Seasonal changes in mesozooplankton swimmers collected by sediment trap moored at a single station on the Northwind Abyssal Plain in the western Arctic Ocean. Journal of Plankton Research 36(2), 490-502.

Martin, D., Claret, M., Pinedo, S., Sardá, R., 1997. Vertical and spatial distribution of nearshore littoral meroplankton off the Bay of Blanes (NW Mediterranean sea). Journal of Plankton Research 19, 2079-2089.

Martín, J., Puig, P., Palanques, A., Ribó, M., 2014. Trawling-induced daily sediment resuspension in the flank of a Mediterranean submarine canyon. Deep Sea Research Part II: Topical Studies in Oceanography 104, 174-183.

Nöthig, E. M. , Kraft, A., Bauerfeind, E., Schröter, F. , Busch, K., Seifert, M., Lalande, C., Salter, I., Soltwedel, T., Knüppel, N. and Lorenzen, C., 2016. Long-term zooplankton swimmer sampling with sediment traps in northeastern Fram Strait in times of global change, ICES/PICES 6th Zooplankton Production Symposium, Bergen, Norway, 9 May 2016 - 13 May 2016

Pagès, F., Martin, J., Palanques, A., Puig, P., Gill, J.-M., 2007. High occurrence of the elasipodid holothurian Penilpidia ludwigi (von Marenzeller, 1893) in bathyal sediment traps moored in a western Mediterranean submarine canyon. Deep-Sea Research Part IOceanographic Research Papers 54, 2170-2180.

Palanques, A., Durrieu de Madron, X., Puig, P., Fabres, J., Guillén, J., Calafat, A., Canals, M., Heussner, S., Bonnin, J., 2006. Suspended sediment fluxes and transport processes in the Gulf of Lions submarine canyons. The role of storms and dense water cascading. Marine Geology 234, 43-61.

Palanques, A., Guillén, J., Puig, P., Durrieu de Madron, X., 2008. Storm-driven shelf-tocanyon suspended sediment transport at the southwestern Gulf of Lions. Continental Shelf Research 28, 1947-1956.

Pinedo, S., Sardá, R., Martin, D., 1996. Seasonal dynamics and structure of soft-bottom assemblages in the Bay of Blanes (Western Mediterranean Sea). Publicaciones Especiales del Instituto Español de Oceanografía 22, 61-70.

Pinedo, S., Sardá, R., Martin, D., 1997. Comparative study of the trophic structure of the soft bottom assemblages in the Bay of Blanes (Western Mediterranean Sea). In: Proceedings of the Fifth International Polychaete Conference. Bulletin of Marine Science 60, 529-543.

Puig, P., Canals, M., Company, J.B., Martin, J., Amblas, D., Lastras, G., Palanques, A., Calafat, A.M., 2012. Ploughing the deep sea floor. Nature 489, 286-289.

Puig, P., X. D. d. Madron, J. Salat, K. Schroeder, J. Martín, A. P. Karageorgis, A. Palanques, F. Roullier, J. L. Lopez-Jurado, M. Emelianov, T. Moutin and L. Houpert 2013. Thick bottom nepheloid layers in the western Mediterranean generated by deep dense shelf water cascading. Progress in Oceanography 111, 1-23.

Puig, P., Martin, J., Masque, P., Palanques, A., 2015. Increasing sediment accumulation rates in La Fonera (Palamos) submarine canyon axis and their relationship with bottom trawling activities. Geophysical Research Letters 42, 8106-8113.

Pusceddu, A., Bianchelli, S., Martin, J., Puig, P., Palanques, A., Masqué, P., Danovaro, R., 2014. Chronic and intensive bottom trawling impairs deep-sea biodiversity and ecosystem functioning. Proceedings of the National Academy of Sciences of the United States of America 111, 8861-8866

Ramírez-Llodrà, E., Company, J.B., Sardà, F., Rotllant, G., 2010. Megabenthic diversity patterns and community structure of the Blanes submarine canyon and adjacent slope in the Northwestern Mediterranean: A human overprint? Marine Ecology 31, 167-182. 
Risso, A. (1816). Histoire Naturelle des Crustacés des Environs de Nice. Librairie GrecqueLatine-Allemande, Paris. 175 pp.,

Román S., Vanreusel A., Romano C., Ingels J., Puig P., Company J.B., Martin D. 2016. High spatiotemporal variability in meiofauna assemblages in Blanes Canyon (NW Mediterranean) subject to anthropogenic and natural disturbances. Deep Sea Research I 117, 70-83.

Romano, C., Voight, J.R., Company, J.B., Plyuscheva, M., Martin, D.,. Submarine canyons as the preferred habitat for wood-boring species of Xylophaga (Mollusca, Bivalvia). Progress in Oceanography 118, 175-187.

Romano, C., Coenjaerts, J., Flexas, M.M., Zúñiga, D., Vanreusel, A., Company, J.B., Martin, D., 2013b. Spatial and temporal variability of meiobenthic density in the Blanes submarine canyon (NW Mediterranean). Progress in Oceanography 118, 144-158.

Sánchez-Vidal, A., Canals, M., Calafat, A.M., Lastras, G., Pedrosa-Pàmies, R., Menéndez, M., Medina, R., Company, J.B., Hereu, B., Romero, J., Alcoverro, T., 2012. Impacts on the Deep-Sea Ecosystem by a Severe Coastal Storm. PLoS ONE 7, e30395.

Sardà, F., Company, J.B., Bahamón, N., Rotllant, G., Flexas, M.M., Sánchez, J.D., Zúñiga, D., Coenjaerts, J., Orellana, D., Jordà, G., Puigdefábregas, J., Sánchez-Vidal, A., Calafat, A., Martín, D., Espino, M., 2009. Relationship between environment and the occurrence of the deep-water rose shrimp Aristeus antennatus (Risso, 1816) in the Blanes submarine canyon (NW Mediterranean). Progress In Oceanography 82, 227-238

Sardá, R., Pinedo, S., Martin, D., 1999. Seasonal dynamics of macroinfaunal key species inhabiting shallow bottoms in the Bay of Blanes (NW Mediterranean). Acta Oecologica 20, 315-326.

Seiler, D., Brandt, A., 1997. Seasonal occurrence of planktic Crustacea in sediment trap samples at three depth horizons in the Greenland Sea. Polar Biology 17, 337-349.

Sevastou, K., Corgosinho, P.H.C., Martinez-Arbizu, P., 2012. A new species of Dahmsopottekina (Copepoda: Harpacticoida: Huntemanniidae) from the western Mediterranean deep sea. Journal of the Marine Biological Association of the United Kingdom 92, 1043-1055.

Silver MW, Gowing MM. 1991.The particle flux: origins and biological components. Progress In Oceanography 26,75-113

Steinberg, D.K., Pilskaln, C.H., Silver, M.W., 1998. Contribution of zooplankton associated with detritus to sediment trap 'swimmer' carbon in Monterey Bay, California, USA. Marine Ecology-Progress Series 164, 157-166.

Tecchio, S., Ramírez-Llodrà E., Aguzzi J., Sánchez-Vidal A., Flexas M. M., Sardà F., Company J.B. 2013. Seasonal fluctuations of deep megabenthos: Finding evidence of standing stock accumulation in a flux-rich continental slope. Progress in Oceanography 118, 188-198.

Thistle D., Ertman S.C., Fauchald K. 1991. The fauna of the HEBBLE site: patterns in standing stock and sediment- dynamic effects. Marine Geology 99,413-422

Vetter, E.W., Dayton, P.K., 1998. Macrofaunal communities within and adjacent to a detritusrich submarine canyon system. Deep-Sea Research Part Ii-Topical Studies in Oceanography 45, 25-54.

von Marenzeller, E., 1893. Zoologische Ergebnisse. I. Echinodermen, gesammelt 1890, 1891 und 1892. Berichte der Commission für Erforschung des Östlichen Mittelmeeres.V. Denkschriften der Mathematisch-Naturwissenschaftlichen Classe der Kaiserlichen Akademie der Wissenschaften, vol. 60, pp. 1-24.

Zúñiga, D., Flexas, M.M., Sánchez-Vidal, A., Coenjaerts, J., Calafat, A., Jordà, G., GarcíaOrellana, J., Puigdefàbregas, J., Canals, M., Espino, M., Sardà, F., Company, J.B., 2009. Particle fluxes dynamics in Blanes submarine canyon (Northwestern Mediterranean). Progress in Oceanography 82, 239-251. 


\section{Figure Captions}

Fig. 1 Bathymetric map showing the location of mooring sites inside in Blanes Canyon (BC) and on the adjacent SW open slope (OS). Labels indicate the location (i.e., BC or OS) and the approximate bottom depth (in meters) of the moorings. Bathymetric contours are every $100 \mathrm{~m}$.

Fig. 2 Timetable of the sediment traps data gathered during the PROMETEO project (from November 2008 to May 2009) Lines show the actual sampling period of each trap. Blanes Canyon (BCdepth); Open slope (OSdepth).

Fig. 3 Time series of current velocity (Speed., a-d panels) and potential temperature ( $\theta$, e-f panels) at $300 \mathrm{~m}, 900 \mathrm{~m}, 1200 \mathrm{~m}$ and $1500 \mathrm{~m}$ inside Blanes Canyon (BC). Black arrows mark the four storms (28 Nov. 2008; 26 Dec. 2008; 24 Jan. 2009; and 25 Apr. 2009) that had an impact on near-bottom current. WIW: Mediterranean Intermediate Water; nWMDW: Western Mediterranean Deep Water. For the current velocity: raw data are shown in gray; data obtained after applying a moving average of span $=50$ ( 25 hours) in black. For potential temperature only data with a moving average of span $=50$ are shown.

Fig. 4 Time series of current velocity (a-c panels), potential temperature ( $\theta$, d panel), and salinity $(S$, e panel) at 900, 1200, 1500 and 1800 m deep on open slope (OS). nWMDW: Western Mediterranean Deep Water. For the current velocity: raw data are shown in gray; data obtained after applying a moving average of span $=50$ ( 25 hours $)$ in black. For potential temperature only data with a moving average of $\operatorname{span}=50$ are shown.

Fig. 5 Relative contribution(\%)of each higher taxonomic group to the total abundance of swimmers captured in the traps along the study period. Copepods are shown separately from other Crustacea to stress their dominance.

Fig. 6 Mean annual flux per trap for each sediment trap inside and outside Blanes Canyon; A: with copepods; B: without copepods.

Fig. 7 A: Relative abundance of the main identified taxa (copepods are shown separately from Other Crustacea); B: Abundance of the different taxa for each trap (copepods have been excluded to better distinguish the contributions of the remaining taxa).

Fig. 8 MDS plot based on the matrix of the mean annual flux of swimmer taxa (pooled by class) per trap. The Blanes Canyon (BC) and open slope (OS) trap groups obtained in the cluster analysis $($ similarity $=70 \%)$ are superimposed on the plot.

Fig. 9 MDS plot based on the complete trap series collected from 900 to $1200 \mathrm{~m}$ depth. A: the groups obtained in the cluster analysis are superimposed on the plot that shows two main groups for Blanes Canyon (BC) and the open slope (OS) (similarity $=40 \%$ ). Bubbles indicate the abundance of Copepods (B), Penilpidia ludwigi (C) and Parateclaia euromarge (D). 
Fig. 10 Total Swimmer and Copepoda fluxes, expressed in number of individuals per $\mathrm{m}^{2}$ and day, throughout the year at the different depths sampled inside Blanes Canyon.

Fig. 11 Total Swimmer and Copepoda fluxes, expressed in number of individuals per $\mathrm{m}^{2}$ and day, throughout the year at the different depths sampled in the SW open slope.

Fig. 12. Fluxes of mayor benthic and planktonic taxa throughout the year at the different depths sampled inside Blanes Canyon.

Fig. 13. Fluxes of mayor benthic and planktonic taxa throughout the year at the different depths sampled in the SW open slope. 
Fig. 1

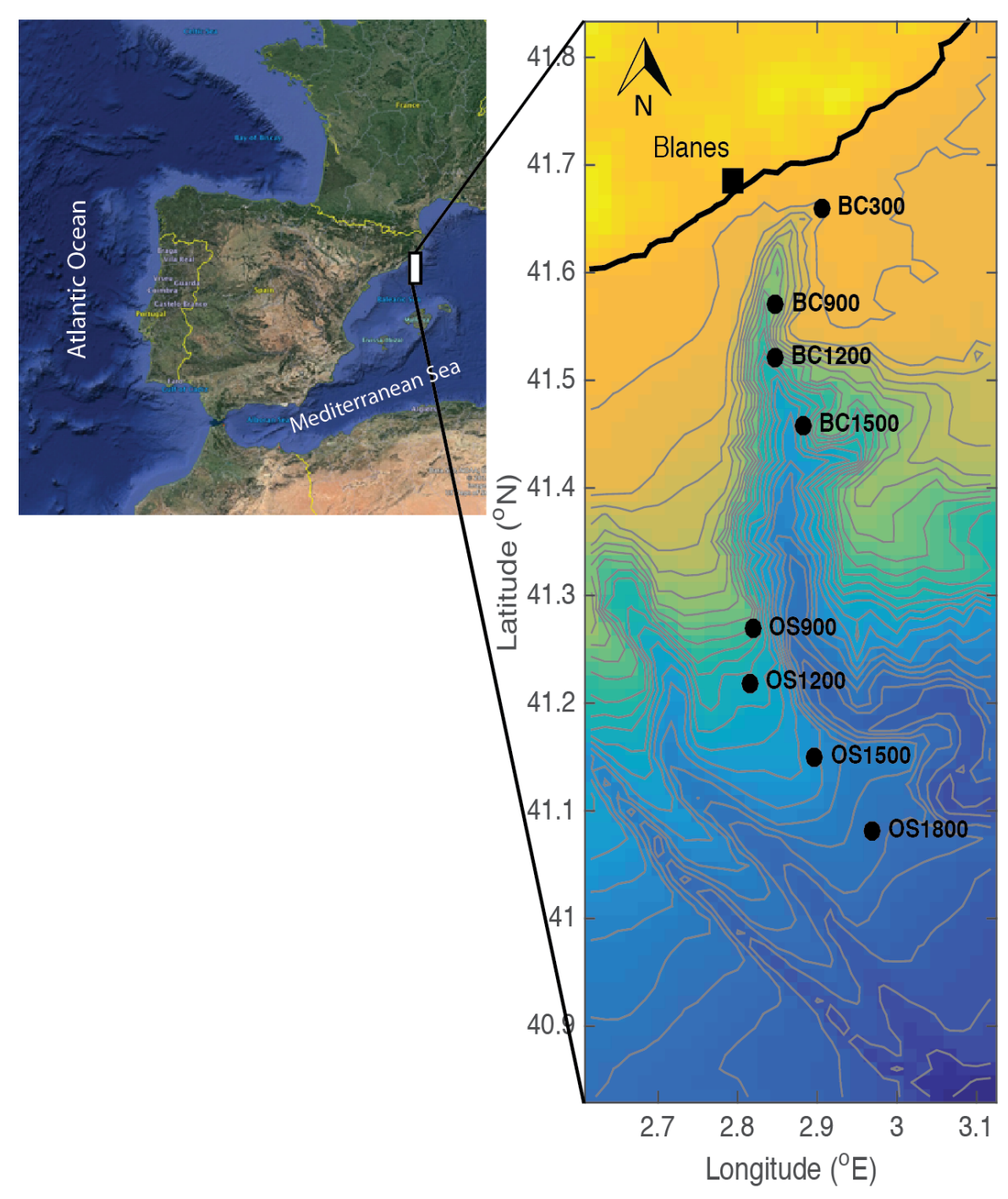


Fig. 2

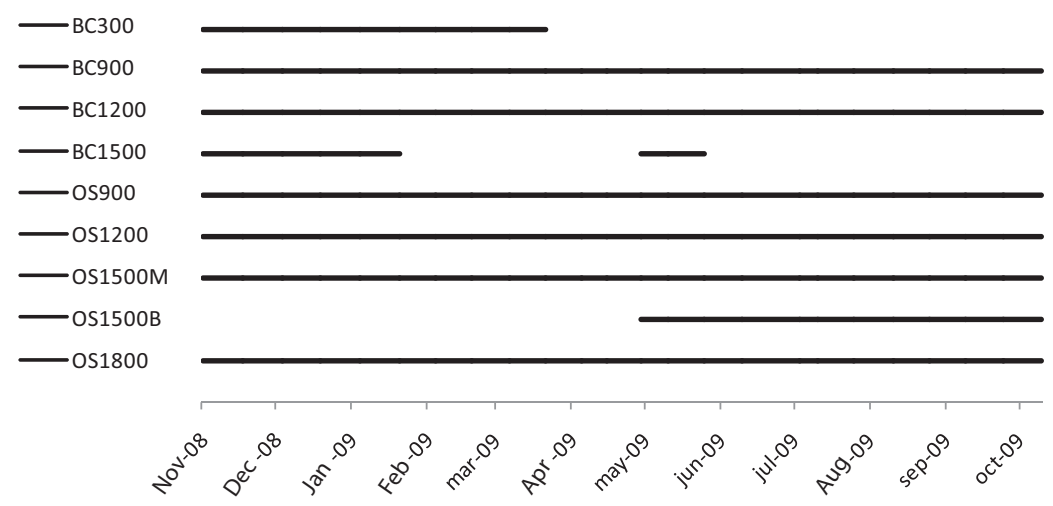


Fig. 3
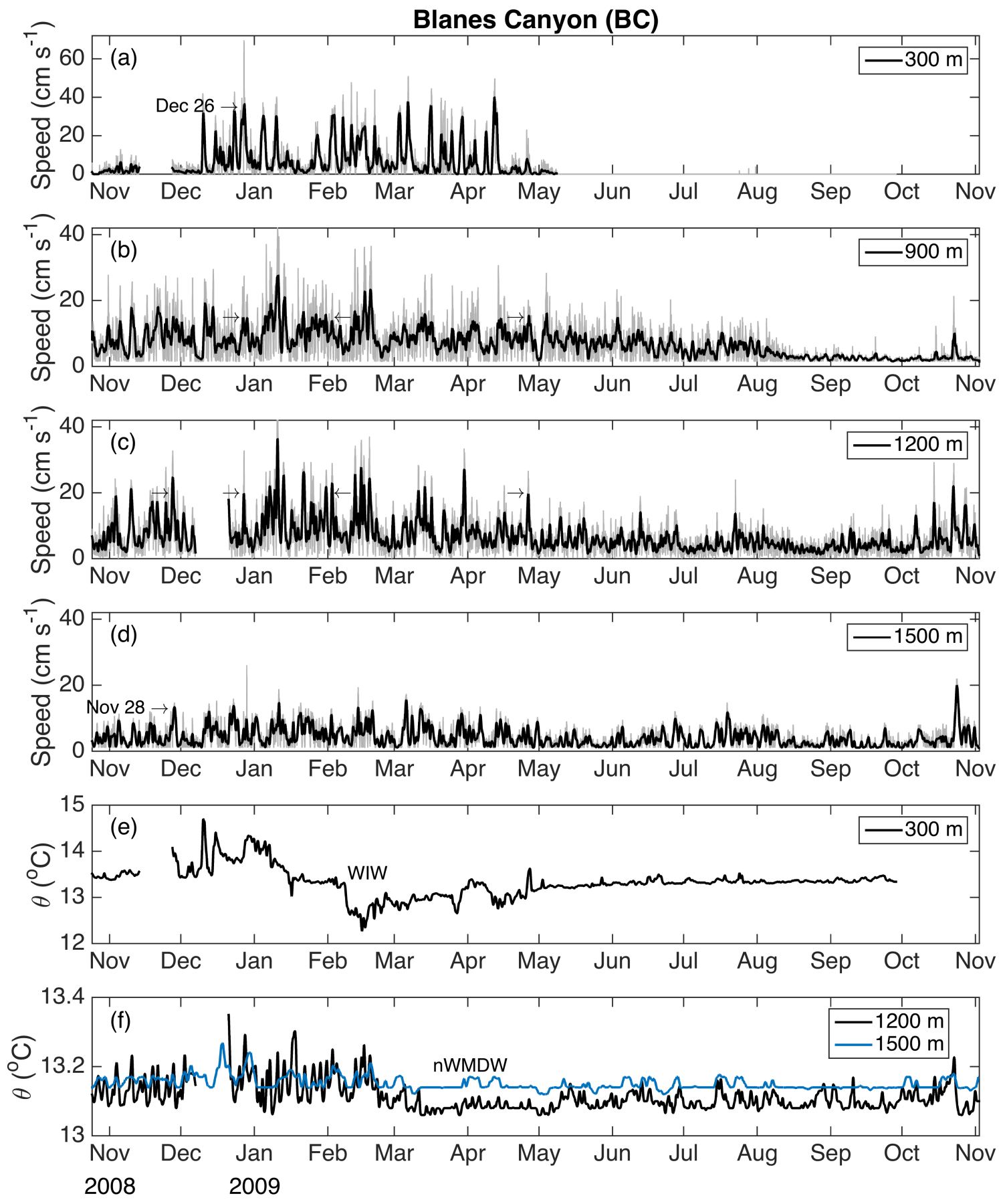
Fig. 4
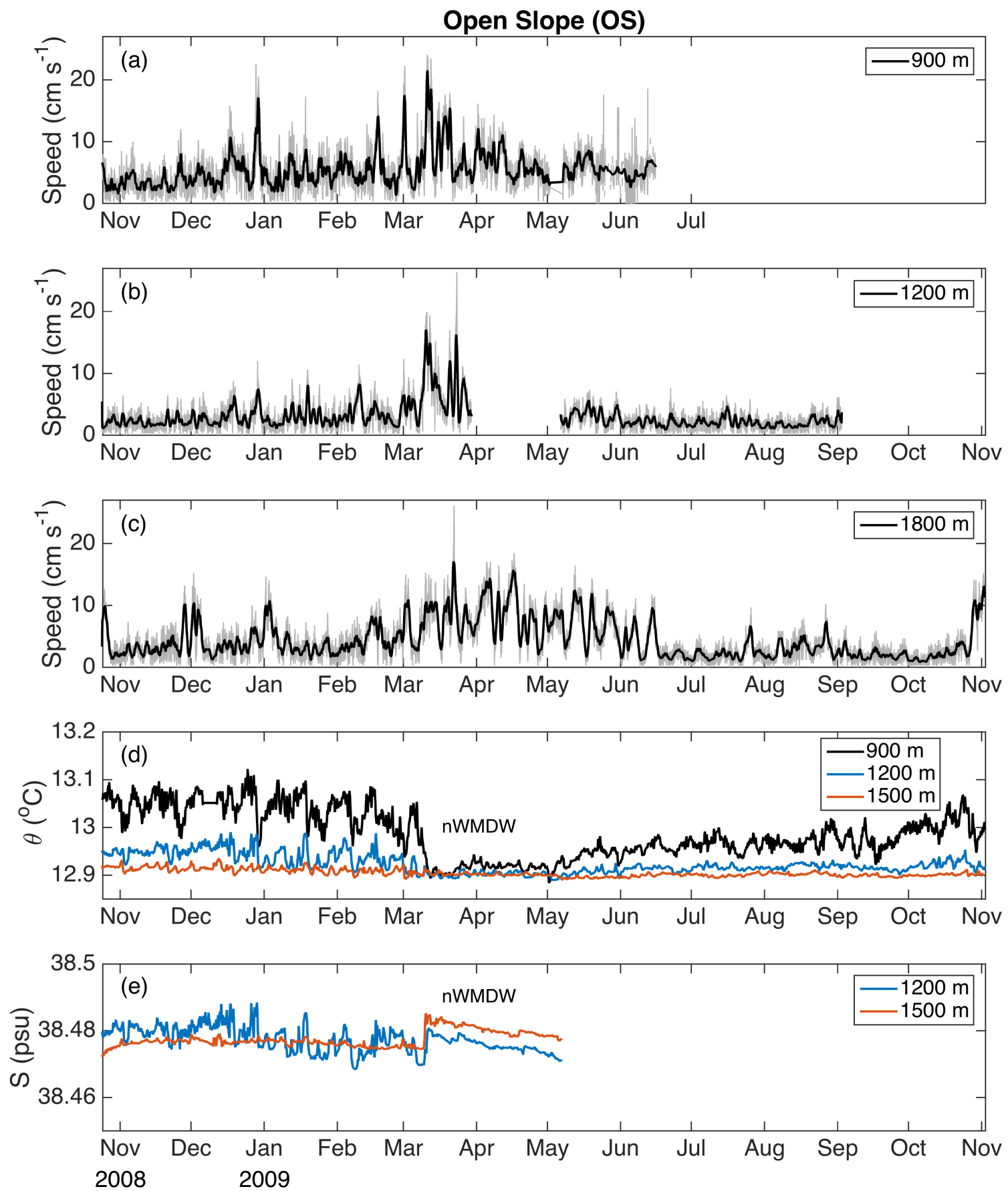
Fig. 5

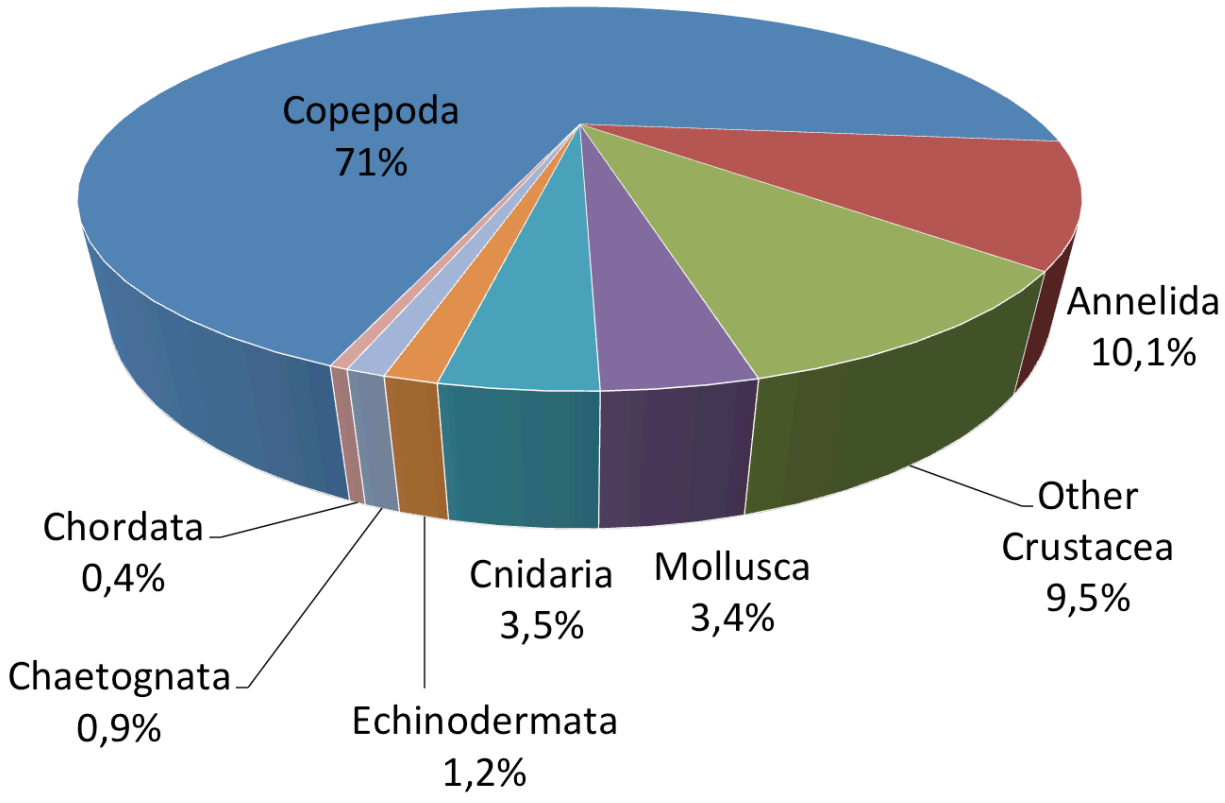


Fig. 6
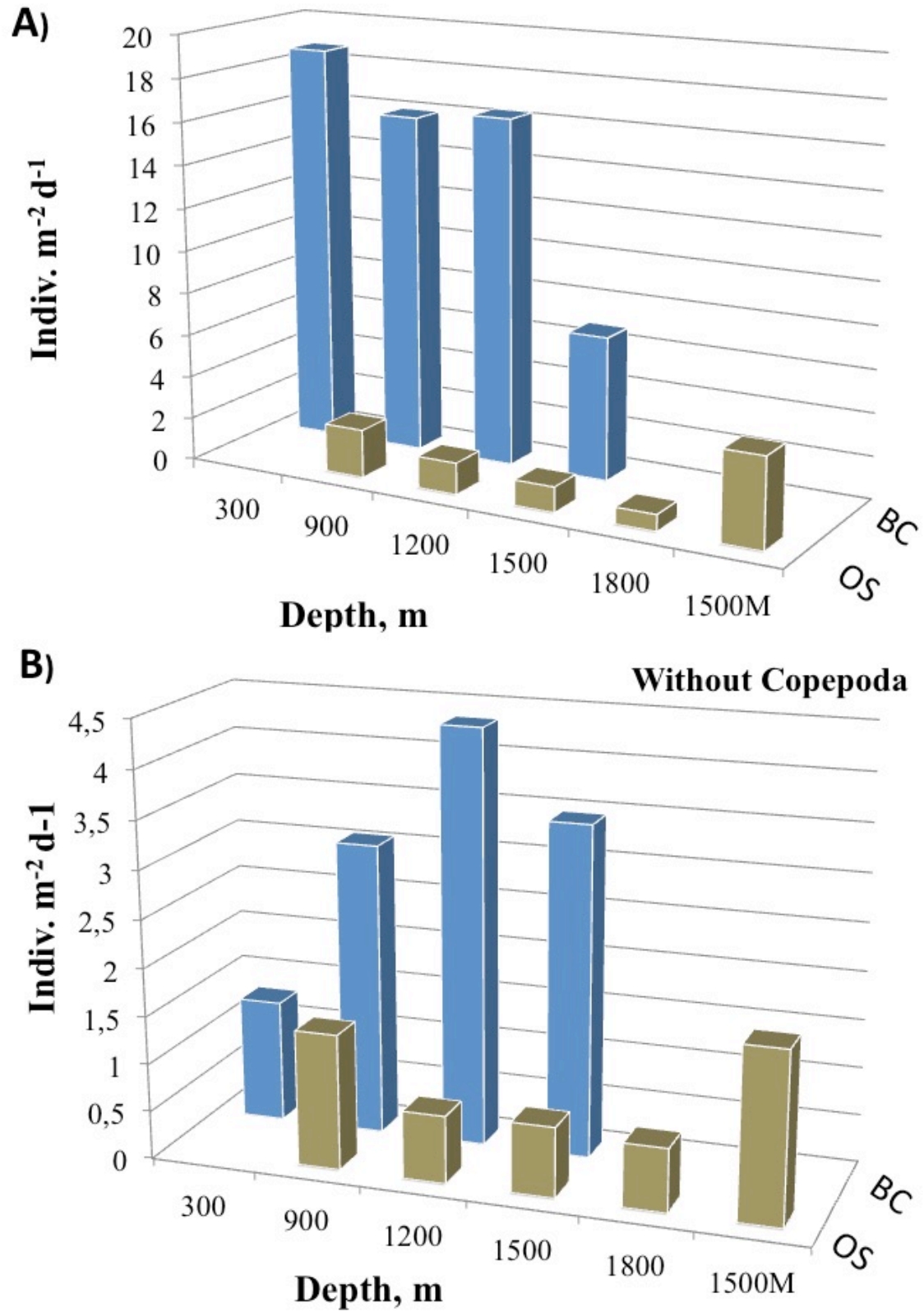
Fig. 7.

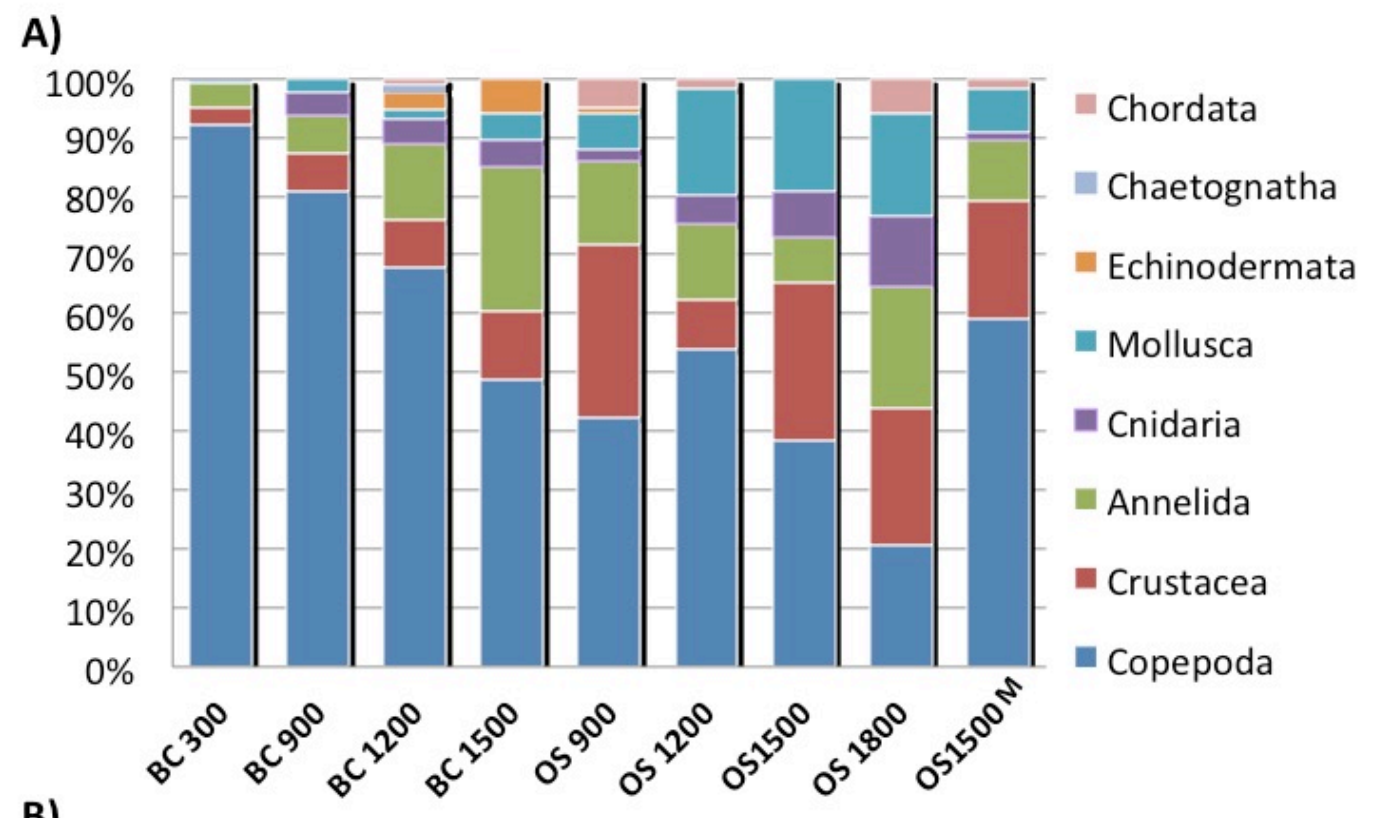

B)

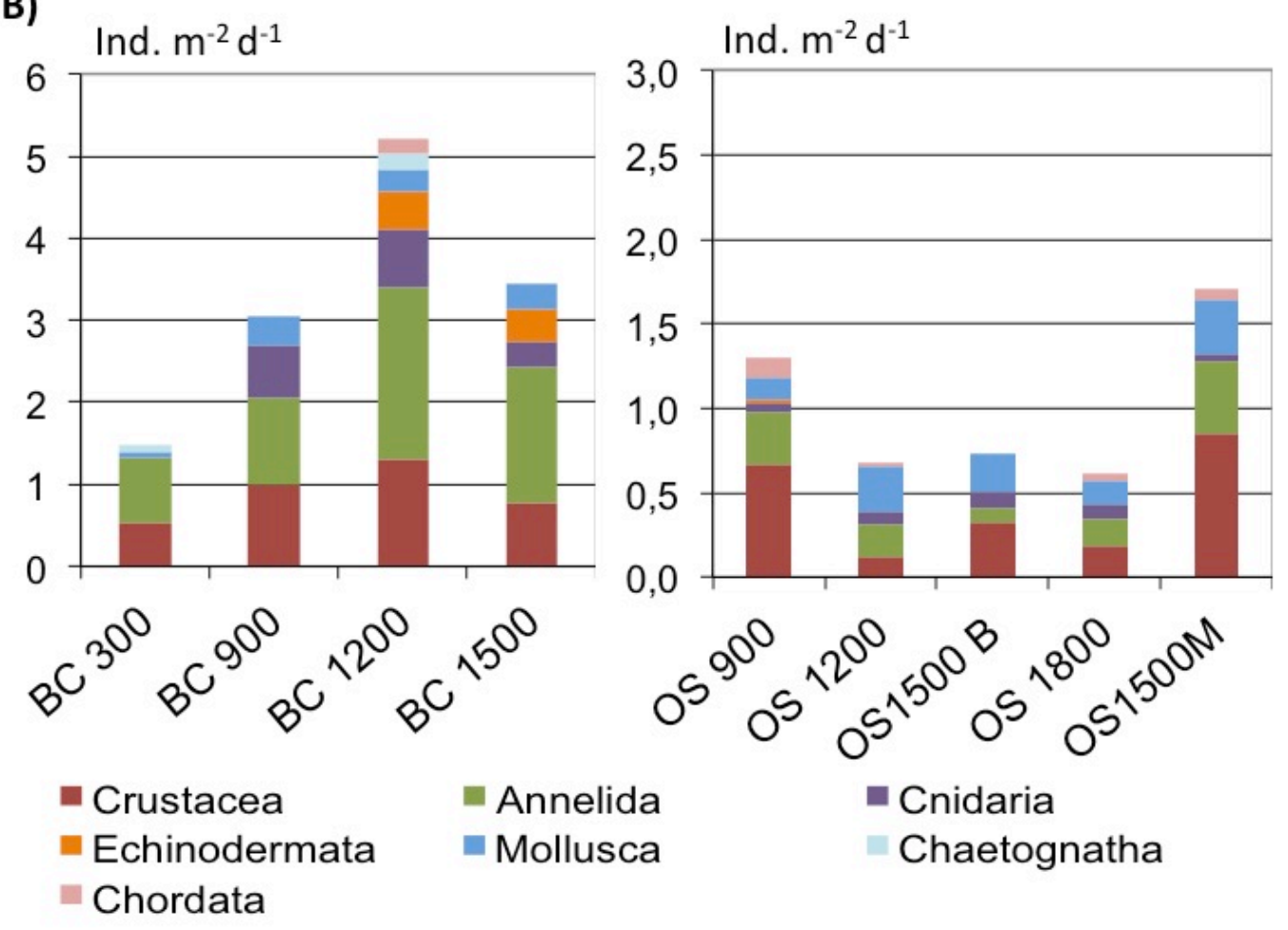


Fig. 8.

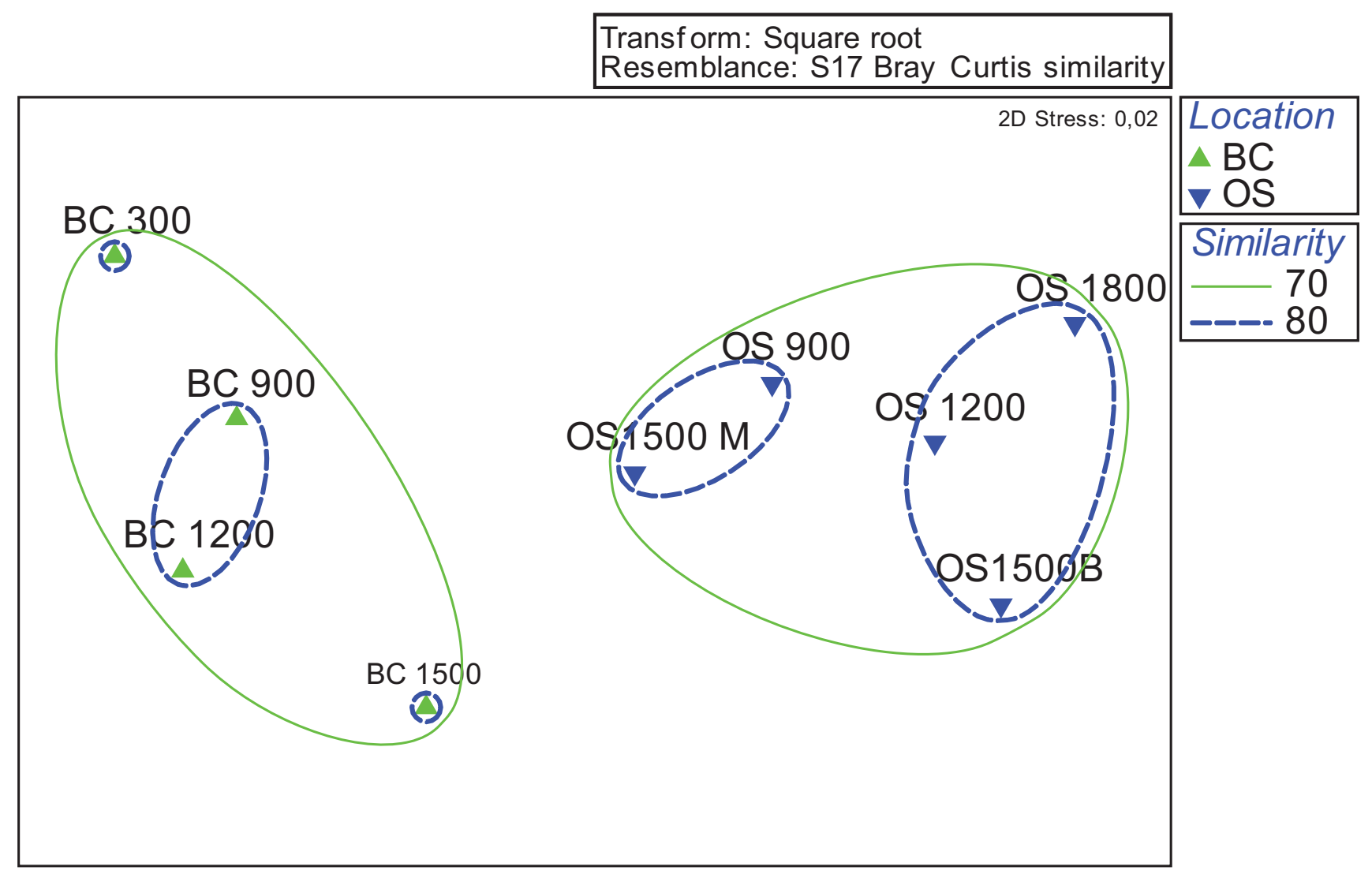


Fig. 9
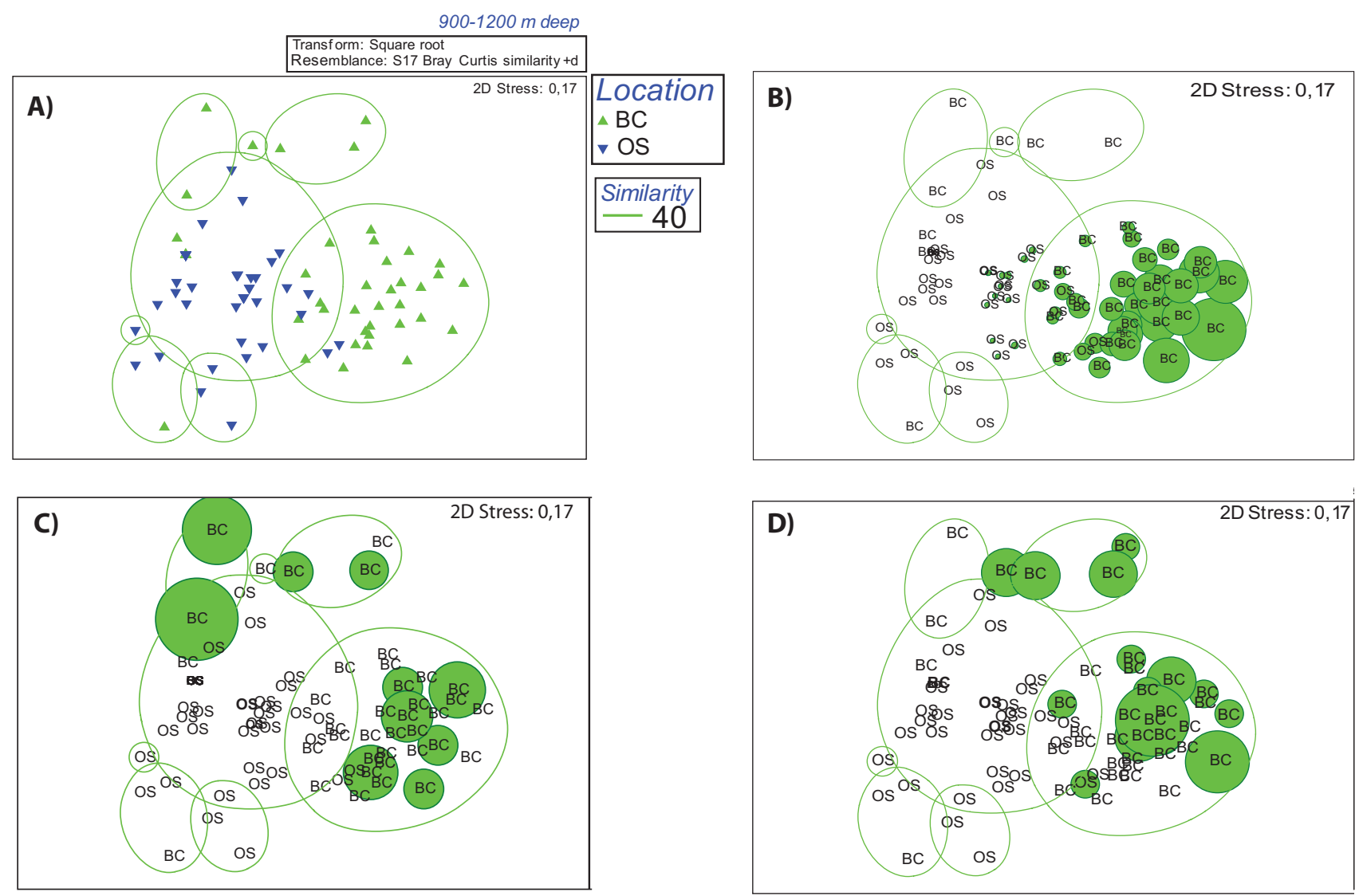
Fig. 10
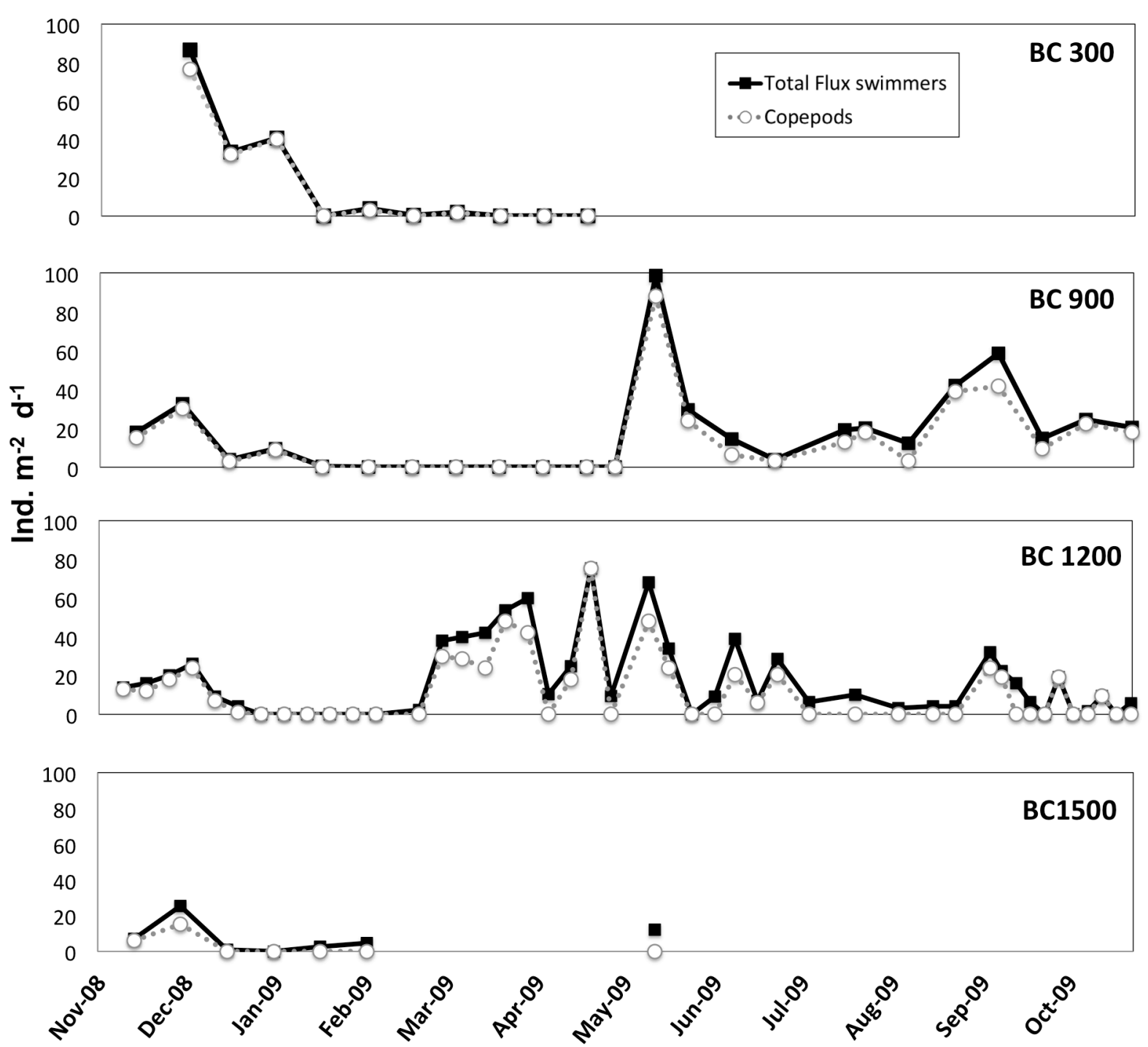
Fig. 11
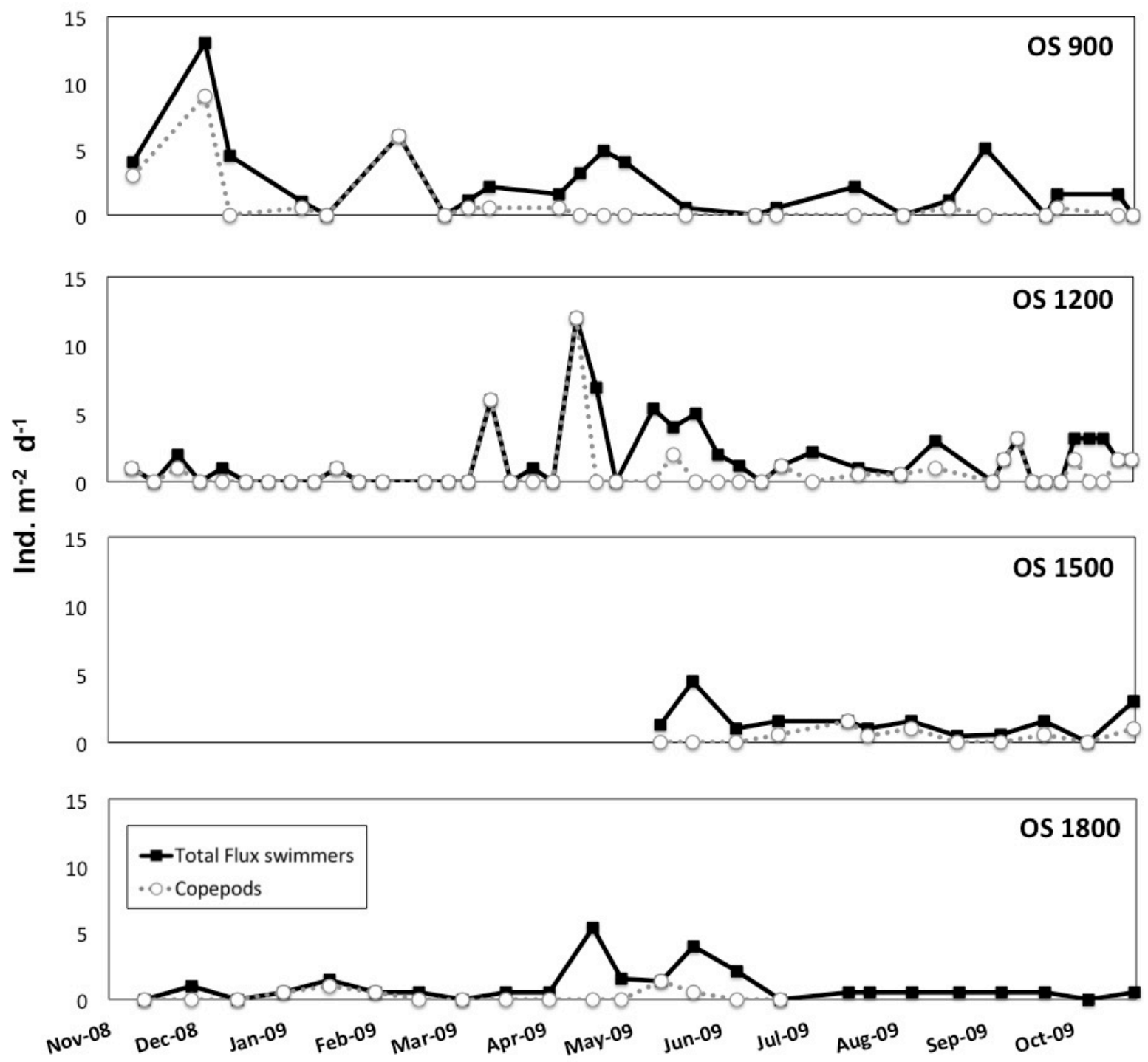
Fig. 12
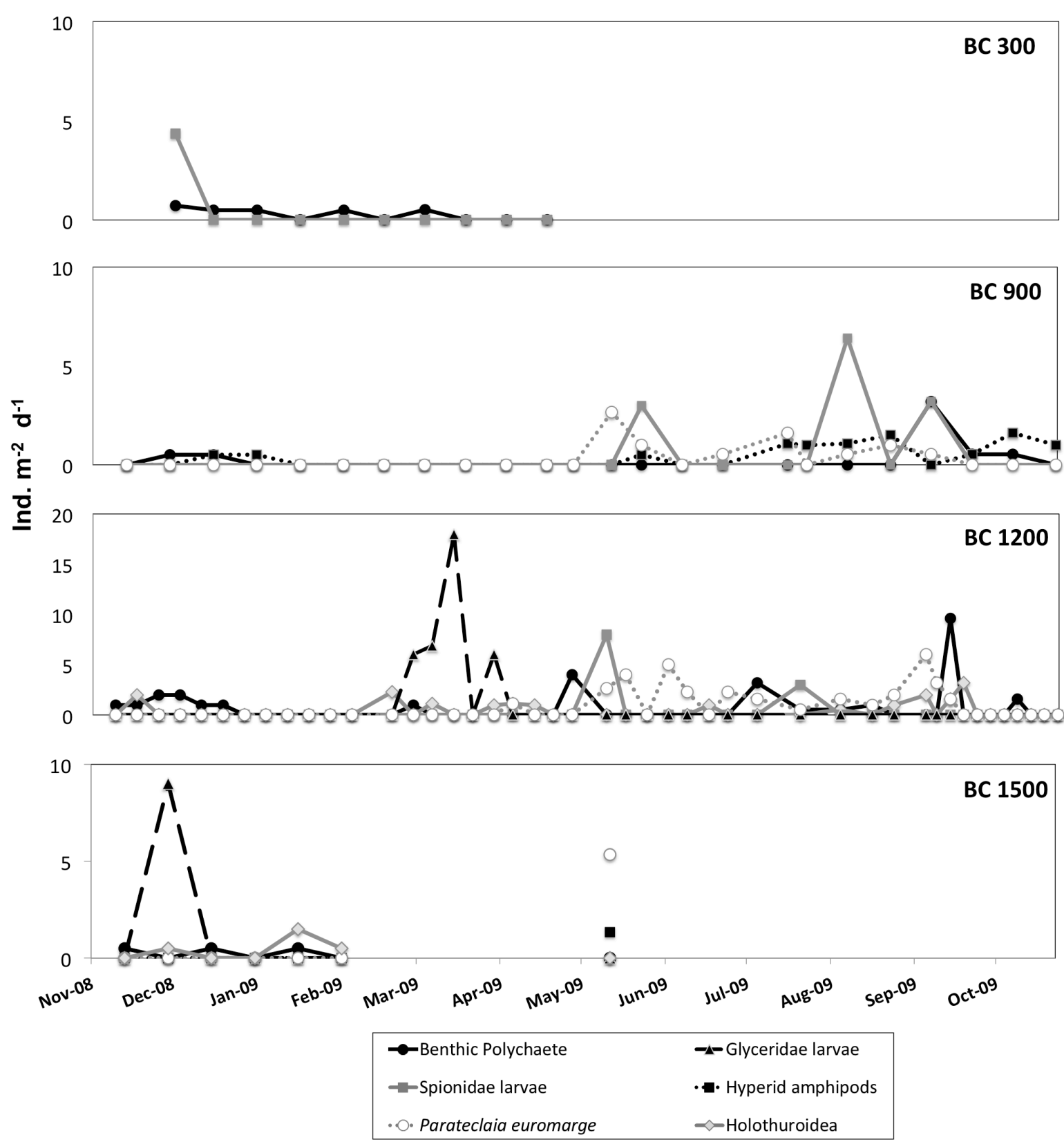
Fig. 13

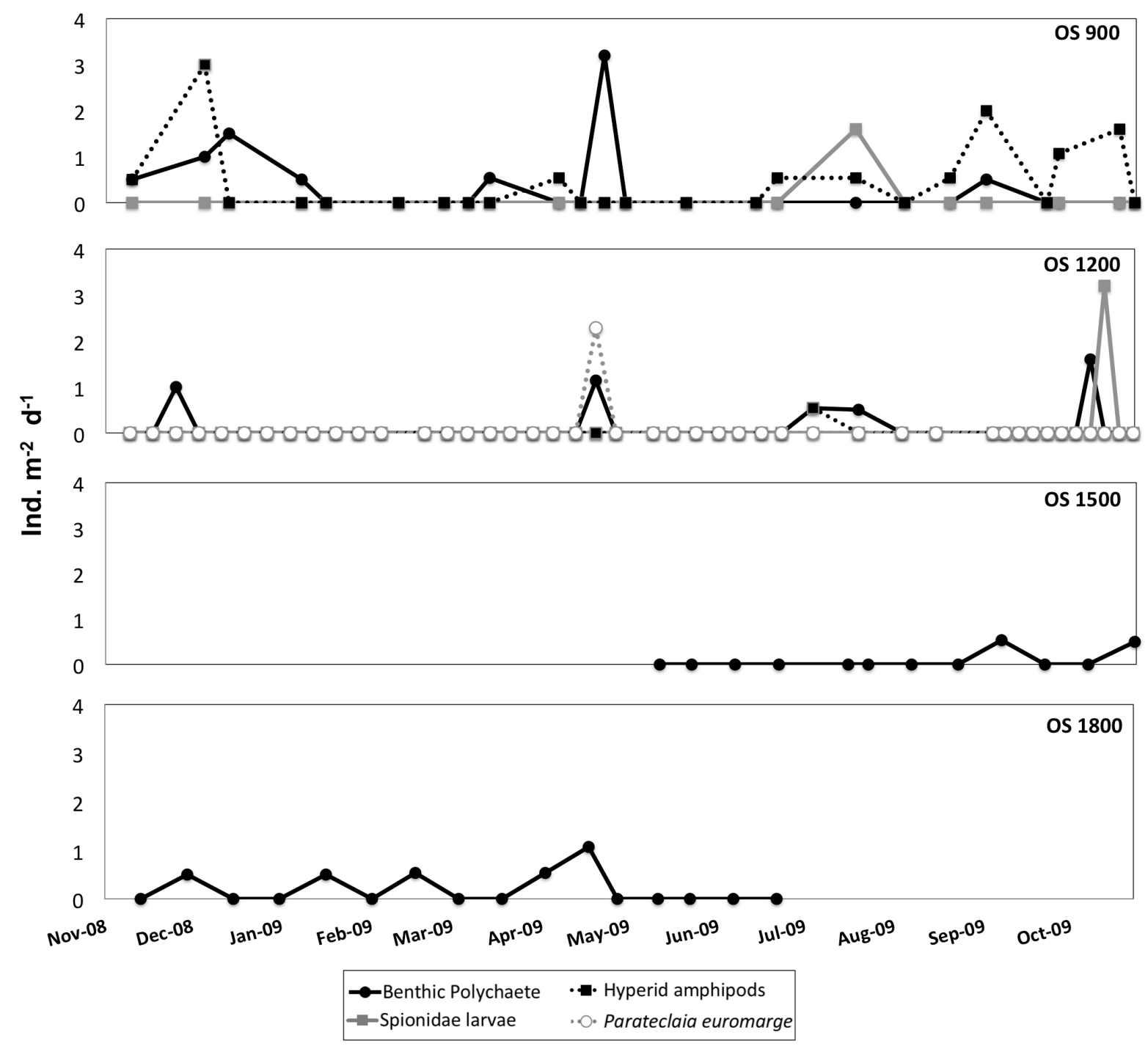

